\title{
EL ROL DEL ADMINISTRADOR PÚBLICO EN CHILE: ¿VALE LA PENA VIVIR PARA ESTE OFICIO? UNA REFLEXIÓN ABIERTA SOBRE LOS DESAFÍOS QUE ENFRENTA LA FORMACIÓN PROFESIONAL UNIVERSITARIA DE CARA AL SIGLO XXI
}

\author{
ÁlVAro V. RAMíreZ-AlujaS (alvaro.ramirez.alujas@gmail.com) \\ Grupo de Investigación en Gobierno, Administración y Políticas Públicas \\ Instituto Universitario de Investigación Ortega y Gasset \\ Universidad Complutense de Madrid, España
}

El artículo presenta un análisis detallado sobre el estado del arte de la carrera de Administración Pública en el contexto del sistema universitario chileno y discute sobre la pertinencia de los actuales perfiles de egreso y la adecuación de los planes de estudio vigentes, desde una perspectiva crítica que contrasta el ámbito de la formación profesional con el espacio laboral y otras variables relevantes. Todo ello sirve de base para reflexionar sobre el presente y futuro de la profesión, en acuerdo a los profundos cambios que ha venido experimentando el Estado y sus instituciones, y a las emergentes tendencias y paradigmas que son la base de un mundo en permanente transición.

Palabras clave: Administración Pública, formación profesional, universidades, educación superior. 


\section{THE ROLE OF THE PUBLIC ADMINISTRATOR IN CHILE: IS IT WORTH LIVING FOR THIS OCCUPATION? AN OPEN REFLECTION ON THE CHALLENGES FACING VOCATIONAL UNIVERSITY TRAINING AT THE DAWN OF THE TWENTY-FIRST CENTURY}

The article presents a detailed analysis of the state of the art of public administration as an undergraduate program in the context of the Chilean university system and discusses the relevance of current graduate profiles and the adequacy of existing curricula from a critical perspective, contrasting vocational training with the workplace, as well as other relevant variables. This provides as a basis for reflecting on the present and future of the profession, mindful of the profound changes in the state and its institutions and emerging trends and paradigms that arise in a constantly changing world.

Keywords: public administration, vocational training, universities, higher education. 


\section{INTRODUCCIÓN ${ }^{1}$}

La pregunta central que sirve de estímulo fundamental a esta reflexión ${ }^{2}-y$ que ha preocupado desde siempre al autor de estas líneas- aspira a ser provocadora y controversial de entrada: ¿Es la carrera de Administración Pública, tal como la conocemos hasta ahora, portadora de futuro laboral, gratificación vocacional y satisfacción personal para quienes la abrazan como opción profesional en sus vidas? No es una pregunta retórica ni tampoco aspira a iniciar un debate epistemológico u ontológico sobre los fundamentos de este oficio o de revisar su posición relativa sobre la base de compararlo con otras profesiones en el mercado laboral chileno. Se trata más bien de comenzar un camino reflexivo para detenernos en aquellas cosas que damos por obvias y que por obvias olvidamos cuando hablamos de formación profesional en el siglo XXI y vocación de servicio público que es, en última instancia, la esencia (si la hay) que sostiene una carrera profesional de esta naturaleza y con las peculiaridades que observaremos más adelante ${ }^{3}$.

Por otro lado y en el intento por responder a la primera pregunta, deberemos transitar -querámoslo o no- por la ruta que nos lleva a indagar sobre el perfil profesional, contenidos formativos (de forma y fondo), metodologías educativas y tantos otros aspectos que son común denominador en las escuelas universitarias que imparten actualmente esta carrera profesional, buscando responder la interrogante de si la oferta formativa disponible (en el mercado de la educación superior chilena) responde al perfil requerido y a la demanda de conocimientos, habilidades, destrezas, actitudes y aptitudes necesarias para que los nuevos egresados

1 El autor agradece el apoyo de la Comisión Nacional de Investigación Científica y Tecnológica (CONICYT) en Chile y la oportunidad de haber podido aprovechar una estadía como investigador visitante en el Centro de Estudios Avanzados en Ciencias Sociales (CEACS) de la Fundación Juan March en Madrid, lugar en el que se gestó el trabajo y las reflexiones que le dan vida y contenido a este artículo.

2 Entendiéndola como un acto en la emoción que consiste en soltar la certidumbre sobre un saber mirando de nuevo si lo que se piensa que es válido, es válido o no (Maturana, 1989).

3 Desde el Instituto de Asuntos Públicos (INAP) de la Universidad de Chile se expresa una aclaradora visión sobre el tema: "El Administrador Público Profesional corresponde a las nuevas profesiones que surgieron en el siglo $\mathrm{XX}$, con rasgos diferentes a las profesiones liberales tradicionales originadas en el siglo XIX. La significación y necesidad de esta profesión ha sido incuestionable tanto por la creciente complejidad de los problemas en que al Estado le compete actuar y por las exigencias de su adecuado manejo por los entes gubernamentales, como por el desarrollo enorme de la especialización profesional, en todos los campos, que caracteriza a los últimos tiempos". Fuente: http://www.inap.uchile.cl/ 
puedan enfrentar adecuadamente los retos y desafíos profesionales, que se asumen como constitutivos de su quehacer, en su progresiva incorporación al espacio laboral y desarrollo de carrera. Lo anterior, va ligado a una reflexión crítica sobre cómo ha ido cambiando (dramáticamente) el mundo de las profesiones en los primeros años del siglo XXI que, llevado al tema que nos ocupa, se traduciría en la siguiente pregunta: ¿Es posible enseñar (en el presente) en base a paradigmas, teorías y marcos analíticos y conceptuales del pasado para ejercer adecuadamente la profesión en el futuro? Esta pregunta se intentará responder desde una mirada transversal sobre el debate que hoy en día se desarrolla acerca de la formación profesional en un contexto de cambios globales y radicales transformaciones en el espacio laboral.

De este modo, desarrollaremos nuestro itinerario sobre la siguiente carta de navegación:

En primer lugar, nos centraremos en los antecedentes disponibles sobre el perfil profesional de la carrera de Administración Pública ${ }^{4}$, contenidos de planes de estudio y otros elementos de relevancia. Sobre dicha base, se contrastará con el análisis de los datos "duros" sobre la situación de la carrera en el mercado laboral y sus consecuencias.

Luego, abordaremos una visión más cualitativa acerca de las características y particularidades de la oferta formativa existente mediante un análisis comparado de las instituciones que imparten la carrera, los contrastes respecto a los perfiles de egreso, mallas curriculares y otros aspectos relevantes a tener en cuenta. En tercer lugar y sobre la base de los hallazgos previos, intentaremos reflexionar sobre los espacios que es necesario considerar para readecuar, renovar y/o reinventar la profesión, en concordancia a los tiempos que se viven y adecuando la matriz de pensamiento a las nuevas realidades y al cambio paradigmático que experimenta el mundo de la educación, el aprendizaje, la gestión del conocimiento y, particularmente, los sistemas políticos, el Estado, la sociedad y las instituciones y servicios públicos, en un esfuerzo por integrar la teoría (formación) con la praxis

4 Normalmente se asume que la formación de esta carrera está orientada preferentemente a la formación de un profesional capaz de participar en los procesos de formulación de políticas públicas y en el ejercicio eficiente y probo de la gestión de organismos públicos. En consecuencia, no constituye su propósito central el estudio de la política en sí misma, sino que aquella es parte de su formación multidisciplinaria. 
profesional (contexto y complejidad del campo laboral preferente para el desempeño de los egresados de la carrera).

Finalmente pero no menos importante, se propondrán una serie de recomendaciones e ideas para cerrar el círculo abierto por las preguntas que son el eje de partida de este ensayo. No se trata tanto de responder adecuadamente a cada una de ellas ni pretender ofrecer "la" respuesta correcta y única a los dilemas planteados, sino más bien sugerir un camino para iniciar y ampliar la reflexión (desde el espacio de soltar las certidumbres y atrevernos a recuperar la curiosidad), reencontrando el sentido abierto de construir colaborativamente una nueva mirada para la carrera, su presente y su futuro, desde la pasión que nos mueve a aquellos que la profesamos ${ }^{5}$ y ejercemos en el entendido que ello se vincula, en lo básico, con el acto de servir a otros, de entregar un servicio en un dominio específico a alguien que lo necesitaba, de dar algo de sí a la comunidad. Al final, todas las profesiones debieran compartir algo elemental que subyace de manera implícita en el sustento ético de ejercerlas en la sociedad (como conjunto de normas morales que rigen la conducta humana) y de lo que actualmente se define como deontología profesional: la acción de poner a disposición de los otros seres humanos nuestros conocimientos, habilidades y talentos para resolver problemas y, en conjunto, alcanzar el bien común y bienestar de la comunidad a la que se pertenece.

\section{SObRe EL (CASi INMUTABLE) PERFIL DE EGRESO DE LA CARRERA DE ADMINISTRACIÓN PÚBLICA: EVIDENCIA RECIENTE Y MARCOS ACTUALES}

Partiremos nuestro viaje considerando como insumo fundamental para la reflexión los criterios de evaluación establecidos en su momento por la Comisión Nacional de Acreditación de Pregrado (CNAP), organismo dependiente del Ministerio de Educación que ya no se encuentra en funcionamiento por los cambios aplicados en la normativa y regulación del ámbito del aseguramiento de la calidad

5 De acuerdo a la establecido en el Diccionario de la Real Academia Española, la palabra profesión (Del lat. professão, -ōnis) puede entenderse como: 1. f. Acción y efecto de profesar; 2. f. Ceremonia eclesiástica en que alguien profesa en una orden religiosa; y 3. f. Empleo, facultad u oficio que alguien ejerce y por el que percibe una retribución. Fuente: RAE (2011). 
en la Educación Superior en Chile 6 , presentando una breve síntesis del marco de referencia sobre el cual se desarrollaron los procesos de acreditación de las universidades que imparten la carrera de Administración Pública (por lo menos hasta el año 2007) y del enfoque que, pese a los cambios experimentados en dichos procesos en la actualidad, sigue vigente y apela a un tipo de perfil de egreso y contenidos del plan de estudio que es necesario observar en detalle para poder evaluar su pertinencia y adecuación al actual contexto laboral y profesional que enfrentan los egresados.

\subsection{El perfil (profesional) de egreso de la carrera de Administración Pública}

De acuerdo a la CNAP (2007), el Administrador Público es:

un profesional, formado con los conocimientos y las metodologías de las ciencias y tecnologías propias de la función pública, en especial las relativas a las áreas de administración, ciencias políticas, derecho, economía, finanzas, sociología, psicología y otras disciplinas afines.

La motivación principal del administrador público es el bien común como razón última de su accionar. Entiende que las consecuencias de sus decisiones modifican y alteran las condiciones de vida de los ciudadanos, por lo tanto, su accionar debe estar observado por las normas y preceptos que define la ética pública.

La formación del Administrador Público entrega y desarrolla conocimientos, criterios, habilidades, competencias y vocación necesarios para desempeñarse profesionalmente en organizaciones del sector público, en las funciones de

6 De acuerdo a lo establecido en la Ley 20.129 y a lo acordado en la séptima sesión de la Comisión Nacional de Acreditación - Chile (organismo encargado de verificar y promover la calidad de la Educación Superior), de fecha 7 de marzo de 2007, mientras la Comisión no cuente con criterios, normas y procedimientos propuestos por sus Comités Consultivos, se aplicarán transitoriamente aquellos definidos por las Comisiones Asesoras de Evaluación de la Calidad de la Educación Superior, Comisión Nacional de Acreditación de Pregrado (CNAP) y Comisión Nacional de Acreditación de Postgrados (CONAP). Fuente: http://www.cnachile.cl/. Por otro lado, gran parte de la reflexión presentada en el artículo obedece a la experiencia y conclusiones a las que el autor ha llegado como miembro del Comité de pares evaluadores en procesos de acreditación de la carrera años atrás. 
planificación, organización, dirección y control, en los distintos niveles que las conforman. Del mismo modo, podrá desempeñarse en organizaciones del sector privado con y sin fines de lucro nacionales e internacionales, en las materias de su competencia.

Finalmente, se plantea que el Administrador Público es un profesional que al aprobar el plan de estudios de la carrera, podrá obtener el grado académico de Licenciado, concordante con la formación disciplinaria y metodológica del plan de estudios.

\section{2 Áreas de Formación y Procesos Formativos en la carrera de Adminis- tración Pública}

Por otro lado, dentro del marco de referencia para los procesos de acreditación se establecía que el plan de estudios conducente al título profesional de Administrador Público debe considerar tres áreas de formación, sin perjuicio de la flexibilidad e integración curricular que determine cada Unidad, de acuerdo a sus orientaciones específicas, estrategias y políticas institucionales (CNAP, 2007). Ellas son:

1. Área de formación básica: la formación básica de los programas conducentes al título profesional de Administrador Público debe contener los conocimientos fundamentales de las ciencias administrativas, ciencia política, el derecho, economía, las ciencias sociales, matemáticas, estadística, metodologías de la investigación y otras disciplinas que contribuyan a su formación;

2. Área de formación profesional: esta área de los programas conducentes al título profesional de Administrador Público incluye todos los conocimientos, técnicas, instrumentos y metodologías propias del ejercicio profesional del egresado; $\mathrm{y}$

3. Área de formación general o complementaria: corresponde al conjunto de actividades académicas orientadas a la formación integral del Administrador Público.

Lo anterior, debiera reflejarse de manera operacional y expresarse de manera nítida en los procesos formativos orientados a la concreción del perfil profesional propuesto y sobre dicha base, las universidades chilenas debieran orientar su accionar. Ello, según la CNAP, obedecía a cumplir y desarrollar rigurosamente dos 
ámbitos de trabajo claramente delimitados en el proceso de formar Administradores Públicos que son:

a) Conocimientos: El programa debe permitir en el estudiante la adquisición de los conocimientos necesarios para su desempeño profesional en las siguientes áreas:

- Ciencias Administrativas, las cuales incluyen entre otras, desde el punto de vista administrativo, planificación, dirección y control; desde el punto de vista de la organización, gestión de personas, contabilidad, finanzas, marketing público, gestión de recursos tecnológicos.

- Ciencias Políticas, las cuales incluyen entre otras, ciencia política, relaciones internacionales, políticas públicas.

- Ciencias Jurídicas, las que incluyen entre otras, derecho constitucional, derecho administrativo, derecho internacional público.

- Ciencias Sociales, las que incluyen sociología y psicología.

- Ciencias Económicas, las que incluyen entre otras, micro economía, macro economía y economía del sector público.

- Otras Ciencias y Disciplinas Complementarias, las que incluyen entre otras, métodos cuantitativos, idiomas, computación y metodología de la investigación.

b) Habilidades, Capacidades y Competencias: El programa debería también permitir la adquisición de habilidades, capacidades y competencias inherentes a un Administrador Público para:

- Comunicarse de manera efectiva a través del lenguaje oral y escrito, y del lenguaje técnico y computacional necesario para el ejercicio de la profesión.

- Utilizar el conocimiento, la experiencia y el razonamiento para crear y emitir juicios fundados.

- Identificar problemas, planificar y enfrentar estrategias de solución.

- Crear, liderar y formar parte de equipos de trabajos, actuando como agente de cambio.

- Motivar la inquietud y búsqueda permanente de nuevos conocimientos y capacidad de aplicarlos y perfeccionarlos. 
- Asumir y cautelar principios éticos.

- Respetar y desarrollar el bien común, con especial preocupación por la comunidad toda.

- Comprender los aspectos interdependientes del mundo globalizado, respetando la identidad nacional y local.

- Ser un agente mediador y negociador en el contexto en que se desempeńa.

\section{UNA MIRADA A LA SITUACIÓN ACTUAL DE LOS PROFESIONALES EGRESADOS DE ADMINISTRACIÓN PÚBLICA: INTERPRETANDO LOS DATOS DEL SERVICIO DE INFORMACIÓN DE LA EDUCACIÓN SUPERIOR (SIES) DEL MINISTERIO DE EDUCACIÓN}

Recientemente, el Ministerio de Educación ha puesto en marcha una potente iniciativa que permite acceder a información detallada, actualizada y clave sobre educación superior y futuro laboral, en particular a datos de egresados, por carrera y por institución, ingresos percibidos y posibilidades que tienen de encontrar trabajo, entre otros tópicos. Tal como lo indica su sitio Web, el Servicio de Información de Educación Superior (SIES) entrega información confiable y oportuna sobre carreras e instituciones para los postulantes, sus familias, académicos, investigadores y la comunidad en general ${ }^{7}$ (SIES/MINEDUC, 2011). Ello contribuye directamente a reducir las asimetrías de información como insumo fundamental para la toma de decisiones respecto a la elección de una carrera universitaria, sus posibilidades de encontrar empleo y desarrollo en el mercado laboral, y la consistencia académica y robustez institucional (en términos comparados sobre: acreditación, calidad docente y solvencia económica) de las universidades que actualmente las imparten.

7 En su sitio Web (Futuro Laboral) actualmente informa sobre 181 carreras profesionales y técnicas, que concentran más del $90 \%$ de los titulados en todo el país. Contiene información renovada anualmente, sobre: a) Ingresos y dispersión que obtienen los profesionales y técnicos después de titularse; b) Probabilidad de tener un trabajo remunerado (empleabilidad) después de la titulación; y c) Información de Contexto de la Carrera: matrícula, titulación, deserción de primer año, duración real de los programas, distribución por tipo de establecimiento de origen y el rango de costo anual de la carrera. Para mayor información: http://www.futurolaboral.cl 
A continuación, revisaremos brevemente algunos de los indicadores que se han podido recopilar de la base de datos SIES en términos de disponer de una visión panorámica sobre la carrera de Administración Pública ${ }^{8}$, sus principales características y elementos distintivos en lo que respecta a la relación con las oportunidades en el mercado del trabajo y niveles de ingreso, e información de contexto sobre la misma dentro del sistema universitario chileno. Dicha información será presentada sobre la base de dos ámbitos de interés para los fines de este trabajo: a) Información agregada sobre características de las universidades que imparten la carrera actualmente (lo que aglutina datos que van desde el valor de los aranceles y duración de estudios hasta el número de titulados); y b) Información agregada sobre características del mercado laboral relativo a los egresados/titulados de la carrera (que va desde las remuneraciones al nivel de empleabilidad).

\subsection{Sobre aranceles, matrícula, tasa de retención y titulados (Universidades)}

Rangos de aranceles: Como se puede observar (Gráfico 1), el rango de aranceles anuales varía entre tramos que van de los 0,5-0,9 millones de pesos ( 3 casos) hasta más de 3 millones de pesos ( 5 casos), con un porcentaje relevante concentrado entre los 1,5-1,9 millones de pesos (11 casos) y entre 2,0-2,4 millones de pesos (7 casos).

\footnotetext{
Un detalle que es menester tener en cuenta en la información analizada es que la carrera se presenta/cataloga como Administración Pública y Ciencias Politicas, y no sabemos si metodológicamente responde a la suma de ambos grados sin distinción (como ocurre en la realidad), por lo que se asume que los datos disponibles debieran corresponder, en casi su totalidad, a la carrera que otorga el título profesional de Administrador Público (y sus respectivas menciones o especializaciones de egreso).
} 


\section{Gráfico 1}

Número de programas por rango de arancel (en millones de pesos)

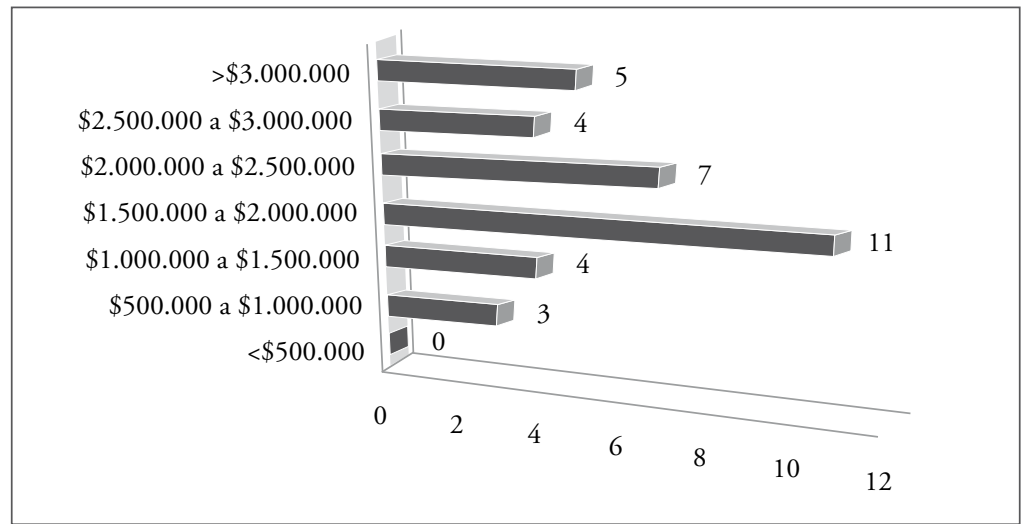

Nota: Corresponde al número de programas de estudios que se ofrecen de esta carrera para cada rango de valores de aranceles anuales de los mismos, según la información de Oferta Académica 2010. Fuente: SIES/MINEDUC (2011).

Matrícula (primer año y total por género): Es posible constatar que en términos relativos el porcentaje de matriculados supera los 1.000 estudiantes anualmente y que la matrícula total en las universidades que imparten la carrera asciende a 4.892 (Gráfico 2). Adicionalmente, se observa un cierto equilibrio en la representación por género, tanto en primer año (con un $44,8 \%$ de mujeres y un $55,1 \%$ de hombres) como en el total de la muestra (con un $48,3 \%$ de mujeres y un $51,7 \%$ de hombres) que presenta una tendencia similar contrastada en términos globales. 


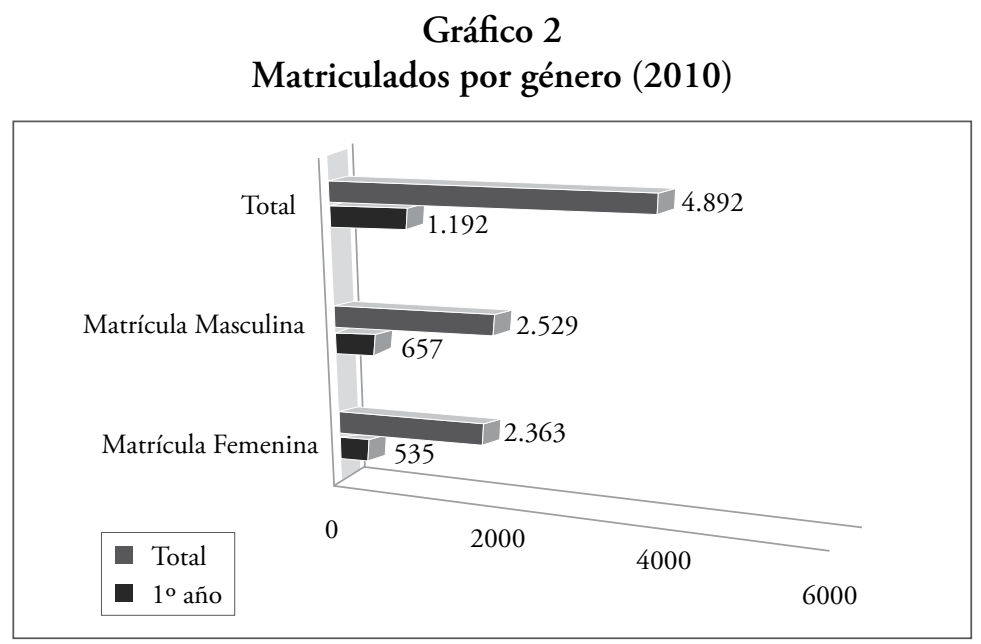

Fuente: SIES/MINEDUC (2011).

Tasa de retención (primer y segundo año): $\mathrm{Al}$ revisar esta información" (Gráfico 3), podemos constatar que existe un $10 \%$ de deserción entre el primer y segundo año de carrera, cifra del todo razonable y que ayuda a explicar la tendencia del número de matriculados comparando el primer año con el total visto en el gráfico anterior.

\section{Gráfico 3}

Retención al primer y segundo ańo (cohorte 2008)

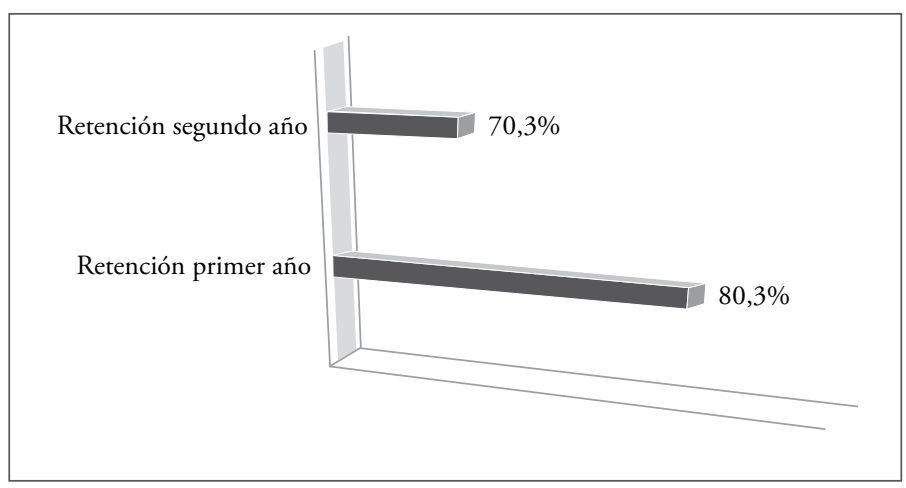

Fuente: SIES/MINEDUC (2011).

9 La retención de primer año es el cociente entre el número de estudiantes que ingresan como alumnos de primer año y el número de esos mismos estudiantes que se mantienen como estudiantes antiguos en la misma institución al año siguiente. $\mathrm{Al}$ respecto, los datos de retención de primer ańo y segundo año se han obtenido a partir de los matriculados de la cohorte 2008. 
Origen educativo: Otro interesante dato dice relación con la distribución de los estudiantes según establecimiento educacional de origen (Gráfico 4). Esto corresponde a la información sobre los porcentajes que representan dentro de la matrícula total 2010 de la carrera los estudiantes que provienen de establecimientos municipales, particulares subvencionados y particulares pagados. Como se observa, el $51 \%$ de los estudiantes proviene de establecimientos particulares subvencionados y luego se ubican los que provienen de la educación municipal (32\%) y de la particular pagada (17\%).

\section{Gráfico 4 \\ Distribución según establecimiento educacional de origen (matrícula 2010)}

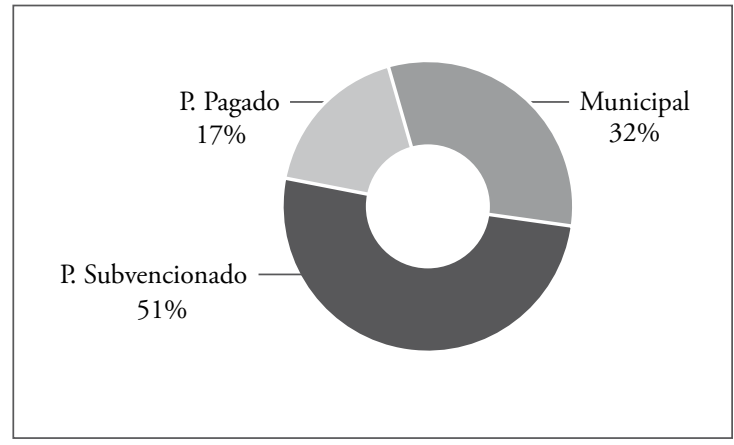

Fuente: SIES/MINEDUC (2011).

Titulados: Finalmente y no menos importante, es necesario revisar el número de titulados y el contraste con la duración (formal y real) de los estudios (Gráfico 5). En primer término, observamos un equilibrio parcial de titulados por género (tendencia similar a los matriculados), aunque se titulan más mujeres (55\%) que hombres (44\%), frente a un total de 521 profesionales para el año 2009. En tal sentido y como discutiremos más adelante, no existe un espacio tan "competitivo" en el mercado laboral (como es el caso de otras profesiones afines como ingeniería comercial, derecho o administración de empresas) dado que la oferta de profesionales se dispersa por todo el territorio nacional y el número de universidades (públicas y privadas) que actualmente imparten la carrera de Administración Pública son solamente diez. 


\section{Gráfico 5}

Número de titulados 2009

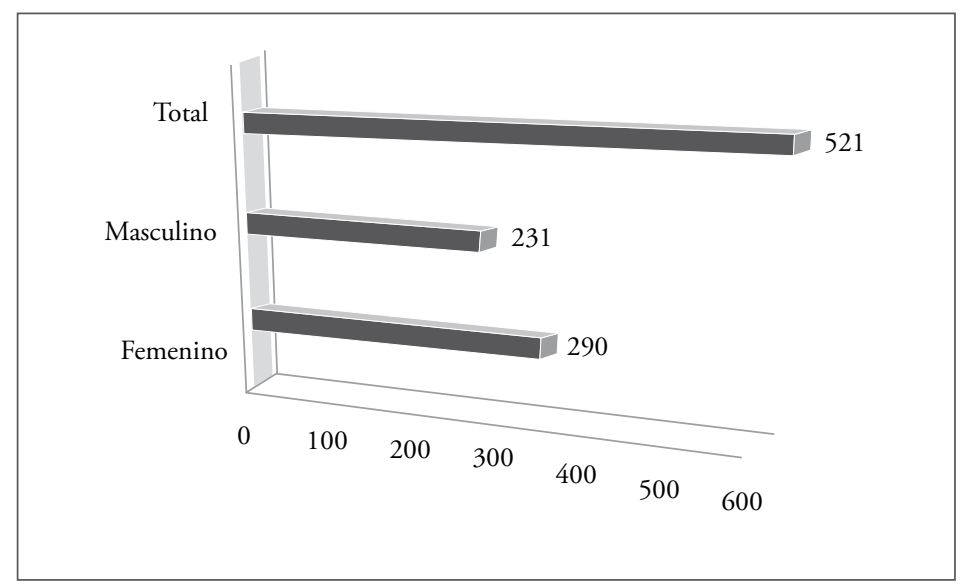

Fuente: SIES/MINEDUC (2011).

Por último, un dato que es necesario tener presente dice relación con la duración de los estudios. Al respecto el SIES entrega información sobre la base de los siguientes conceptos (Gráfico 6): a) La duración formal de la carrera se refiere al número promedio de semestres en que esté distribuido el plan de estudios de la carrera más el proceso de titulación, según lo informado por las instituciones que imparten la carrera; y b) La duración real de la carrera es el número promedio de semestres que demoran los estudiantes, desde que ingresan al primer año de la carrera hasta que se titulan. El dato de duración real en este caso se ha obtenido a partir de los titulados del año 2009 (y se han considerado sólo los programas informados como regulares de 4 o más semestres que tengan información de más de 20 titulados). 


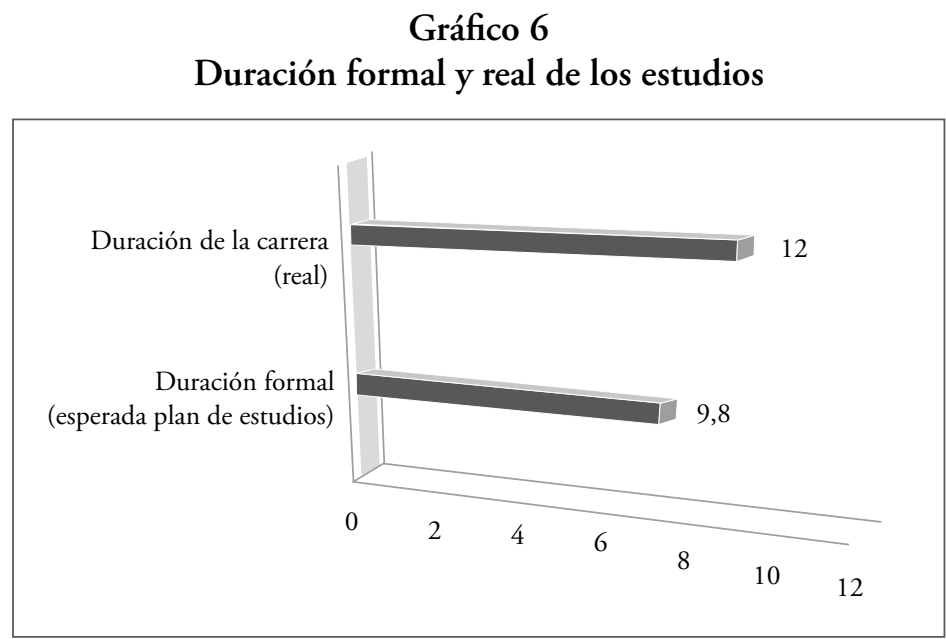

Fuente: SIES/MINEDUC (2011).

Al observar la duración de los estudios constatamos una diferencia de algo más de un año entre la duración formal y la real, distancia que es bastante positiva si se compara con otro tipo de profesiones y/o estudios donde existe, con toda seguridad, una mayor variabilidad en este índice (como el caso de derecho, arquitectura y algunas ingenierías, según los propios datos de SIES).

\subsection{Sobre remuneraciones promedio, evolución y tramos de ingresos, y empleabilidad}

En relación al ingreso promedio ${ }^{10}$ (Gráfico 7 ), podemos apreciar lo siguiente: Por un lado, que los ingresos brutos mensuales entre el primer y cuarto ańo de ejercicio profesional de los titulados, tienden a un aumento progresivo cuyas (pequeñas) fluctuaciones pueden obedecer a diversas causas (como por ejemplo, a escalas de salarios del sector público y sistemas de contratación existentes como contrata y/u honorario que se ajustan a determinadas funciones y grados dentro

10 De acuerdo a la información disponible en SIES, conviene señalar que: a) Los ingresos al cuarto año después de su titulación corresponden a los ingresos percibidos por la cohorte de titulados 2005; b) Los ingresos al tercer año después de su titulación corresponden al promedio de ingresos percibidos por las cohortes de titulados 2005 y 2006; c) Los ingresos al segundo año después de su titulación corresponden al promedio de ingresos percibidos por las cohortes de titulados 2005, 2006 y 2007; y d) Los ingresos al primer año después de su titulación corresponden al promedio de ingresos percibidos por las cohortes de titulados 2005, 2006, 2007 y 2008. 
de la carrera funcionaria, y que es el terreno preferente de búsqueda de opciones laborales para los egresados), pero que muestran avances sustantivos para una cierta consolidación parcial en el mercado del trabajo de los nuevos profesionales recién titulados.

Otro dato relevante y complementario a estas cifras es que desde SIES se establece un indicador que es el ranking de los mayores ingresos (en dinero de 2010) al primero y cuarto año de egreso, donde la carrera de Administración Pública se encuentra en el décimo lugar. Un dato clave al momento de evaluar las condiciones de empleo y las expectativas salariales.

\section{Gráfico 7}

Ingresos brutos mensuales (en pesos a octubre 2010)

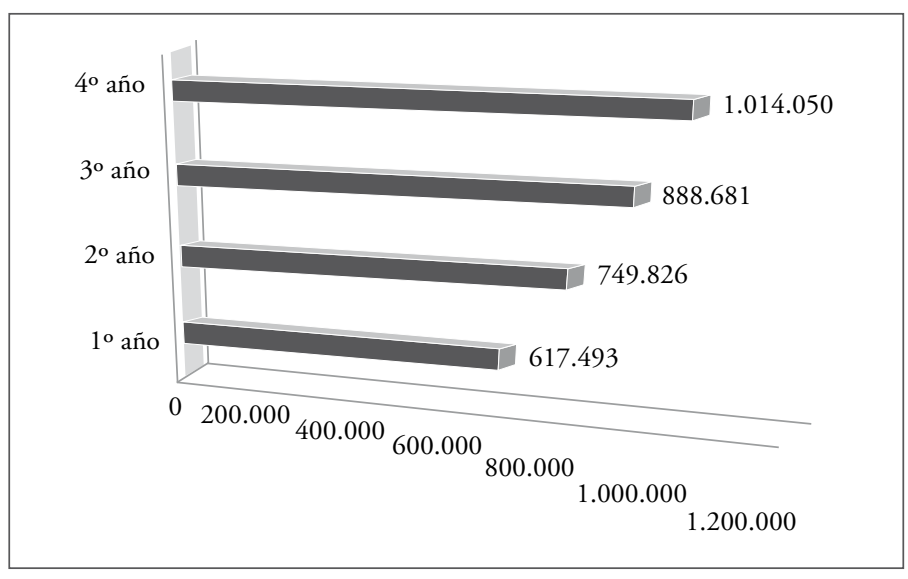

Fuente: SIES/MINEDUC (2011). 
Tramos de ingreso ${ }^{11}$ : Otro dato interesante lo constituyen los tramos entre los titulados "mejor pagados" en el mercado, el promedio y el segmento inferior, considerando los ingresos brutos mensuales por año de incorporación al mercado del trabajo (Gráfico 8). Vemos que en el 10\% superior no existen diferencias profundas entre llevar uno o 4 años de ejercicio profesional, escenario que contrasta con los valores a nivel de promedio, donde efectivamente se da una diferencia de casi un $40 \%$ entre quienes están en su primer año y quienes llevan cuatro años de incorporación al mercado del trabajo. En cualquier caso, existe una cierta estacionalidad en los niveles y tramos de ingresos.

\section{Gráfico 8}

Ingresos brutos mensuales por tramos (en pesos a octubre 2010)

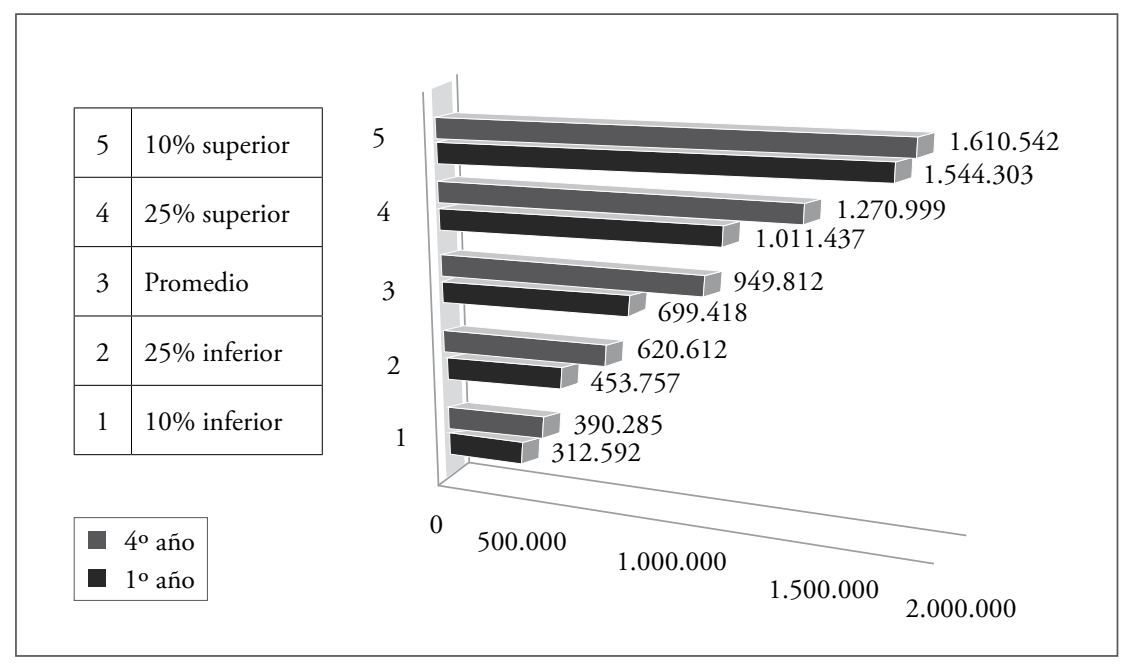

Fuente: SIES/MINEDUC (2011).

11 De acuerdo a SIES: Los tramos de ingresos son una medida que muestra las diferencias de ingresos en una determinada carrera. Por ejemplo, el rango de $10 \%$ superior indica que un $10 \%$ de los titulados de esta carrera gana más que la cifra señalada, mientras que el rango de $25 \%$ inferior indica que un $25 \%$ de los titulados de esta carrera gana menos que dicho monto. Los ingresos al primer año después de la titulación corresponden al promedio de ingresos percibidos por las cohortes de titulados 2005, 2006, 2007 y 2008. Los ingresos al cuarto año después de la titulación corresponden al promedio de ingresos percibidos por la cohorte de titulados 2005 . 
Evolución de ingresos: En relación a lo anterior conviene observar la tendencia y evolución de los ingresos (Gráfico 9). En la información de SIES, ello corresponde al promedio ponderado de los ingresos brutos mensuales de las cohortes 2000 y 2001 para los ocho ańos siguientes posteriores a su titulación.

\section{Gráfico 9}

Evolución de ingresos brutos mensuales (promedio cohortes 2000 y 2001)

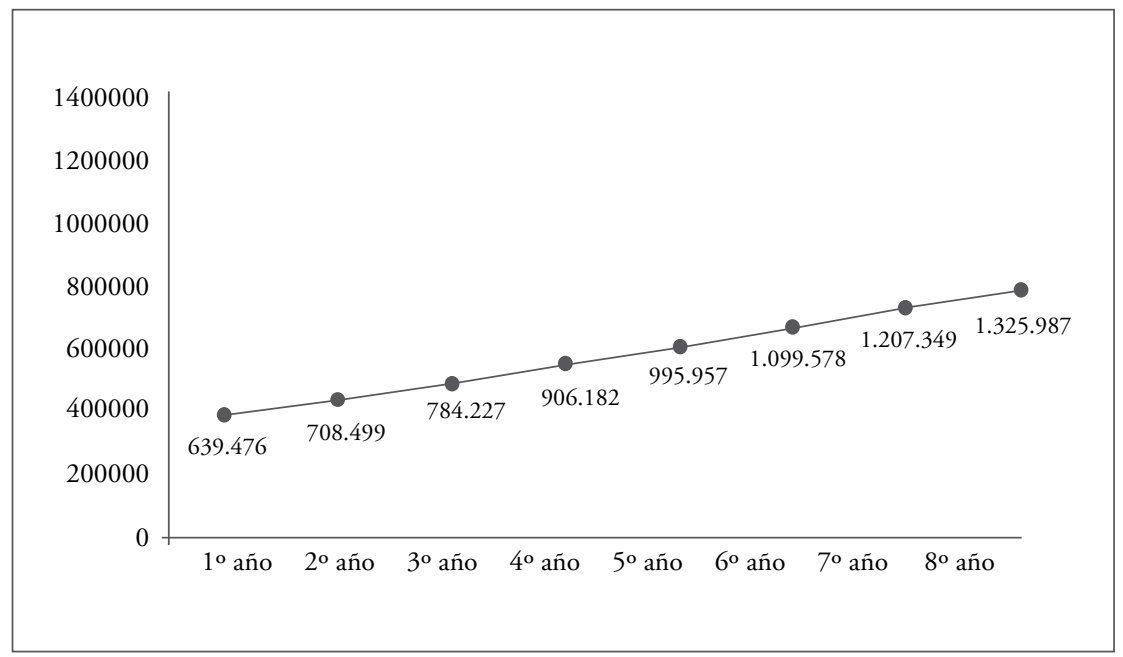

Fuente: SIES/MINEDUC (2011).

Se observa que es factible llegar a duplicar el ingreso inicial percibido entre el séptimo y el octavo año de ejercicio profesional. Ello es demostrativo de que existe una suerte de evolución de los ingresos por año laboral ejercido que contrasta con los datos comentados más arriba (al menos en términos de salario, existe una mínima base de "desarrollo de carrera" que se refleja en incrementos parciales por año trabajado).

Empleabilidad: Finalmente, revisamos uno de los indicadores más importantes y que nos entrega información útil sobre el desenvolvimiento de los titulados en sus primeros pasos en el mercado laboral. De acuerdo a SIES, el indicador de empleabilidad mide la proporción de titulados de una carrera que logra encontrar un empleo al cabo del primer año después de su titulación. Para el caso de los datos presentados (Gráfico 10), la empleabilidad corresponde a la calculada para 
las cohortes de titulados 2005, 2006, 2007 y 2008 para el primer año después de su titulación.

Es necesario destacar que al observar e interpretar los datos, podemos afirmar que más del 80\% de los profesionales de la carrera de Administración Pública/Ciencia Política encuentra trabajo antes de cumplir un año de titulados, detalle no menor en un contexto donde la saturación profesional, la falta de ofertas laborales atractivas y adecuadas al perfil, y la precariedad son parte de los principales problemas en la absorción de nuevos egresados universitarios (lo que en los últimos años ha contrastado con la brecha de empleabilidad que se genera al comparar a los titulados universitarios con los titulados de centros e institutos técnicoprofesionales, lo que es demostrativo de ciertas tendencias vinculadas al carácter más aplicado del conocimiento experto y a la necesidad de recursos humanos de soporte para labores de carácter más técnico y operacional).

\section{Gráfico 10 \\ Empleabilidad al primer año posterior a titulación (cohortes)}

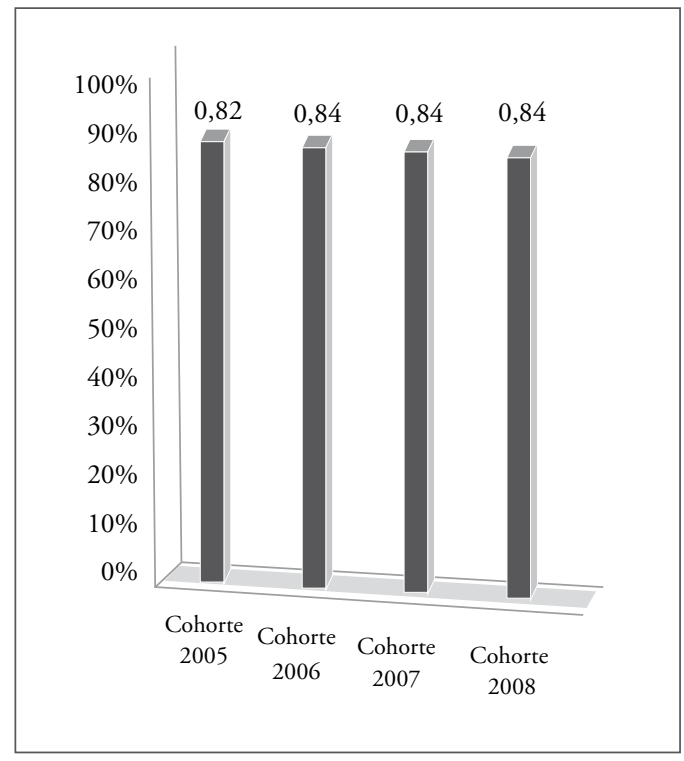

Fuente: SIES/MINEDUC (2011). 


\subsection{Síntesis preliminar}

Como hemos podido apreciar, los titulados de la carrera de Administración Pública gozan en la actualidad de un razonable posicionamiento en el mercado laboral y de niveles más que satisfactorios en lo que respecta a empleabilidad, expectativas salariales y desarrollo de carrera, lo que contrasta con los datos agregados revisados sobre las características que ofrece el sistema universitario chileno en el ámbito de los niveles de matrícula, retención de estudiantes y número de titulados. Entonces, surge la interrogante: ¿Por qué detenerse a cuestionar el modelo formativo y los paradigmas que le dan sustento si, al parecer, responden a lo que la sociedad necesita de esta profesión? ¿De dónde surge la preocupación por ir más allá de la lógica incremental y abogar por cambios sustantivos en el perfil profesional que hoy en día está vigente? Si bien los datos presentados pueden ser útiles para afirmar que no es necesario realizar cambios radicales en los planes de formación y en los enfoques que cruzan la configuración profesional disponible en las universidades chilenas, creemos que ello no garantiza en absoluto que siga siendo una tendencia inmutable en el futuro y más que conformarnos con el panorama analizado nos parece del todo pertinente el avanzar sobre las posibilidades que hoy día existen para exigir más y repensar el espacio profesional en la perspectiva de las profundas transformaciones que, silenciosamente, han venido emergiendo de la mano del nuevo siglo. En parte, ello ha sido asumido por algunas universidades que han dotado de nuevos contenidos y metodologías a sus planes de estudio y han realizado esfuerzos sustantivos por aggiornar sus enfoques. Sin embargo, creemos que ello si bien es necesario, no es suficiente para calibrar y catalizar todas las opciones de futuro que es posible identificar en el horizonte y proyecciones de esta carrera profesional.

En el próximo acápite realizaremos un sencillo ejercicio de comparación sobre las principales características que ofrecen las universidades chilenas que imparten la carrera. Ello será fundamental para el posterior desembarco reflexivo sobre las brechas y vacíos que, como profesión, se deben asumir para hacer frente al nuevo contexto. 


\section{ANÁLISIS COMPARADO SOBRE PERFILES Y PLANES DE ESTUDIO DE LA CARRERA DE ADMINISTRACIÓN PÚBLICA EN CHILE: CONTENIDOS, ENFOQUES E INTERROGANTES}

En el afán de contrastar lo establecido en el marco de referencia para la acreditación de la carrera profesional de Administración Pública (CNAP, 2007) con la oferta e información disponible en las distintas universidades que actualmente la imparten, se presenta un breve análisis sobre el tema. Se trata fundamentalmente de comparar los distintos perfiles de egreso y los planes de estudio (syllabus) o mallas curriculares de las 10 escuelas universitarias que actualmente imparten la carrera de administración pública en Chile (6 públicas y 4 privadas). Ellas son:

1. Universidad de Chile

2. Universidad de Antofagasta

3. Universidad de Concepción

4. Universidad de Los Lagos

5. Universidad de Valparaíso

6. Universidad de Santiago de Chile

7. Universidad Academia de Humanismo Cristiano

8. Universidad Autónoma

9. Universidad Central

10.Universidad San Sebastián

\subsection{Sobre perfil de egreso}

Una mirada comparada a los perfiles de egreso que esbozan las distintas universidades da cuenta de las enormes coincidencias y acuerdos (tácitos) que definirían el sentido de la carrera, las capacidades que se le atribuyen a sus egresados y las características distintivas en su ejercicio profesional (Cuadro 1). 


\section{Cuadro 1}

\section{Perfiles de egreso de las Escuelas de Administración Pública en Chile}

\begin{tabular}{|c|c|}
\hline $\begin{array}{l}\text { Universidad } \\
\text { de Chile } \\
\text { (UCHILE) }\end{array}$ & $\begin{array}{l}\text { Es un profesional universitario formado para desempenarse en el ámbito del } \\
\text { Estado, el gobierno y los asuntos públicos, y está capacitado para: a) Ejercer la } \\
\text { gestión integral de las organizaciones públicas; b) Dirigir personas y equipos de } \\
\text { trabajo en el sector público; c) Conformar y liderar equipos multidisciplinarios } \\
\text { para el diseńo y la gestión de políticas públicas; d) Comprender e interpretar el } \\
\text { entorno complejo en que se desenvuelve, analizándolo en sus diversas perspectivas, } \\
\text { sean estas históricas, sociales, políticas, económicas y culturales; e) Identificar y } \\
\text { reconocer, con responsabilidad, los problemas y necesidades públicas, y orientar } \\
\text { las acciones y servicios para su solución; y f) Desarrollar su acción con visión } \\
\text { estratégica, desempenándose adecuadamente en situaciones de incertidumbre. }\end{array}$ \\
\hline $\begin{array}{l}\text { Universidad } \\
\text { de } \\
\text { Antofagasta } \\
\text { (UANTOF) }\end{array}$ & $\begin{array}{l}\text { Es un profesional con sólidos conocimientos científicos que lo especializan en } \\
\text { el gobierno, la administración del Estado y sus procesos, posee una formación } \\
\text { multidisciplinaria sustentada por principios de transparencia y probidad, lo que } \\
\text { entrega competencias básicas para transformarse en el nexo entre el desarrollo } \\
\text { económico-social y las concepciones políticas de cada gobierno, y las técnicas } \\
\text { administrativas necesarias para la buena conducción de las instituciones } \\
\text { públicas, para ello, posee amplios conocimientos en ciencia política y social, } \\
\text { sólidas bases en teoría económica, planificación y proyectos, y un dominio } \\
\text { completo de las técnicas administrativas modernas. }\end{array}$ \\
\hline $\begin{array}{l}\text { Universidad } \\
\text { de } \\
\text { Concepción } \\
\text { (UDEC) }\end{array}$ & $\begin{array}{l}\text { Es un profesional: a) Multidisciplinario; b) Con una clara vocación de servicio } \\
\text { público, emprendedor e innovador por excelencia; y c) Con un profundo } \\
\text { sentido ético en su formación académica. Los conocimientos adquiridos en las } \\
\text { áreas de la administración, la ciencia política, la economía y el derecho le otorgan } \\
\text { competencias profesionales orientadas: A la toma de decisiones estratégicas en } \\
\text { el ámbito de las políticas públicas; y a ejercer funciones directivas, asesoras y } \\
\text { técnicas a través de la incorporación de modernas y actualizadas herramientas e } \\
\text { instrumentos de gestión. En síntesis, el desarrollo en competencias transversales } \\
\text { le permite enfrentar el medio laboral con espíritu crítico, orientado hacia } \\
\text { el logro de resultados efectivos y eficientes, con capacidad de liderazgo y } \\
\text { responsabilidad social. }\end{array}$ \\
\hline
\end{tabular}

Universidad de Los Lagos (ULAGOS)
Es un profesional que se desempeńa preferentemente en el Estado y en otras organizaciones de carácter público y privado, donde su sólida formación en las áreas socio-política, administrativa, jurídica y económica son altamente valoradas. Posee una visión integral acerca de los asuntos públicos lo que determina su clara vocación por el servicio público, compromiso con la comunidad y con las políticas que direccionan el país. Está capacitado para comprender y explicar complejos fenómenos político-sociales y de gestión administrativa, a través del conocimiento de los fundamentos teóricos, epistemológicos, metodológicos y técnicos. Se distingue por sus competencias para la toma de decisiones, para evaluar la eficiencia de la gestión administrativa, y para medir el impacto de programas y políticas de desarrollo. 


\begin{tabular}{|c|c|}
\hline $\begin{array}{l}\text { Universidad } \\
\text { de Valparaíso } \\
\text { (UV) }\end{array}$ & $\begin{array}{l}\text { Será un profesional calificado, dotado de sólidos conocimientos en las áreas de } \\
\text { Ciencias Sociales, Política, Administración, Derecho y Economía, con una visión } \\
\text { estratégica e integradora y con capacidad de gestión en los órganos e instituciones } \\
\text { del aparato público y con una competencia que le permita asesorar a las } \\
\text { autoridades en la toma de decisiones y en la generación de soluciones alternativas. }\end{array}$ \\
\hline $\begin{array}{l}\text { Universidad } \\
\text { de Santiago } \\
\text { de Chile } \\
\text { (USACH) }\end{array}$ & $\begin{array}{l}\text { El objetivo fundamental de la carrera es la formación de profesionales que } \\
\text { puedan desempeńar funciones creativas de análisis y optimización, con el fin } \\
\text { de maximizar la eficiencia, eficacia y efectividad en la producción de bienes, } \\
\text { servicios y regulaciones por parte del Estado, entendido éste como agente } \\
\text { de concertación y desarrollo de la sociedad. El egresado de la Carrera de } \\
\text { Administración Pública de la USACH es un profesional rigurosamente formado } \\
\text { en las áreas de la Gestión Pública, con especial énfasis en el Gobierno y Gestión } \\
\text { Territorial, la Ciencia Política y las Políticas Públicas, la Economía y el Derecho. }\end{array}$ \\
\hline $\begin{array}{l}\text { Universidad } \\
\text { Academia de } \\
\text { Humanismo } \\
\text { Cristiano } \\
\text { (UAHC) }\end{array}$ & $\begin{array}{l}\text { Los profesionales serán capaces de: a) Diseñar, formular e implementar } \\
\text { políticas, planes y programas, a nivel nacional, regional y local; b) Planificar y } \\
\text { administrar recursos financieros y materiales; c) Gestionar y dirigir a personas; } \\
\text { d) Desarrollar e implementar políticas territoriales, regionales y locales; e) } \\
\text { Utilizar instrumentos de análisis cuantitativos y cualitativos para la mejora } \\
\text { continua del servicio público; f) Controlar la gestión; g) Dirigir instituciones } \\
\text { y organizaciones públicas; h) Gestionar los sistemas contables públicos; i) } \\
\text { Gestionar el presupuesto público a nivel institucional; y j) Dirigir equipos. }\end{array}$ \\
\hline $\begin{array}{l}\text { Universidad } \\
\text { Autónoma } \\
\text { (UA) }\end{array}$ & $\begin{array}{l}\text { Es un profesional, formado con los conocimientos y las metodologías de las } \\
\text { ciencias y tecnologías propias de la función pública, en especial las relativas a } \\
\text { las áreas de administración, ciencias políticas, derecho, economía, finanzas y } \\
\text { otras disciplinas afines. La formación [...] entrega y desarrolla conocimientos, } \\
\text { criterios, habilidades, competencias y vocación necesarios para desempeñarse } \\
\text { profesionalmente en organizaciones del sector público, en las funciones de } \\
\text { planificación, organización, dirección y control, en los distintos niveles que } \\
\text { las conforman. La motivación principal del administrador público es el bien } \\
\text { común como razón última de su accionar. Entiende que las consecuencias de } \\
\text { sus decisiones modifican y alteran las condiciones de vida de los ciudadanos, } \\
\text { por lo tanto, su accionar debe estar observado por las normas y preceptos que } \\
\text { define la ética pública [Nota: Descripción similar a la usada por la CNAP]. }\end{array}$ \\
\hline $\begin{array}{l}\text { Universidad } \\
\text { Central } \\
\text { (UCEN) }\end{array}$ & $\begin{array}{l}\text { La Carrera tiene por objetivo formar profesionales modernos, destinados a } \\
\text { desempeńar funciones directivas, asesoras y técnicas en las diferentes áreas de } \\
\text { gestión de las instituciones, con la misión de enfrentar las crecientes necesidades } \\
\text { de la ciudadanía. }\end{array}$ \\
\hline $\begin{array}{l}\text { Universidad } \\
\text { San Sebastián } \\
\text { (USS) }\end{array}$ & $\begin{array}{l}\text { El alumno obtiene una sólida base de conocimientos sobre la realidad social, } \\
\text { política y económica que se complementa con incorporación de habilidades } \\
\text { analíticas, lo que le permite diseñar y evaluar políticas públicas, de una forma más } \\
\text { certera en la toma de decisiones, con un sentido estratégico que aporta al desarrollo } \\
\text { y modernización del Estado, la sociedad civil y las relaciones internacionales. } \\
\text { Formamos profesionales con sólidas habilidades para el ejercicio de la función } \\
\text { pública moderna y la integración de las distintas variables que influyen en la toma } \\
\text { de decisiones de los ámbitos público, económico, social y político. }\end{array}$ \\
\hline
\end{tabular}

Fuente: Elaboración propia sobre la base de información disponible en las Web institucionales (2011). 
Al mirar en detalle, se constata que existe una tendencia a asignarle un carácter normativo muy profundo tanto a la descripción del perfil de egreso como a las "potenciales" actividades que los titulados deberán desarrollar en su desempeño laboral. Ello, sin lugar a dudas, genera un nivel de expectativas muy alto en quienes deciden optar por estudiar la carrera que presiona fuertemente por su cumplimiento en términos prácticos ( $\mathrm{y}$ puede generar resultados adversos que devengan en frustraciones posteriores y un cierto resentimiento profesional). Por otro lado y comparado con las descripciones de perfil de otras carreras afines (como es el caso de leyes, economía o ingeniería comercial, por ejemplo), el énfasis puesto en las "consecuencias" del actuar del Administrador Público en su ejercicio profesional, vis-a-vis otros oficios, es cuestionable por variadas razones, algunas de ellas "provocadoramente" expresadas para reflexionar sobre las paradojas y peligros que encierran las declaraciones curriculares y formativas:

a) Se asume que la vocación de servicio público exigida a esta profesión es exclusiva y excluyente de quienes la detentan;

b) Se considera, tal vez exageradamente, que por el solo hecho de estudiar la carrera y ejercerla posteriormente, se accederá a los niveles de poder necesarios para generar e impulsar el cambio social en aras del bien común;

c) Establece ex ante una cierta "deontología" (tratado de deberes) que no necesariamente es consistente con el ejercicio profesional en la práctica, que encasilla al profesional a orientar su búsqueda de posibilidades laborales casi exclusivamente dentro del Estado y sus instituciones, y que estimula una suerte de creencia (o mito si se prefiere) en que se está en posesión de una credencial que opera como mecanismo garante de una superioridad moral por sobre el resto de profesiones por el solo hecho de orientarse vocacionalmente al logro del bien colectivo de la sociedad.

\subsection{Sobre Planes de Estudio}

Al observar comparativamente los contenidos fundamentales que sustentan los planes de estudio de las distintas escuelas, encontramos que existen al menos cinco ámbitos de formación "vertebral" o tradicional y que, salvo extrańas excepciones, se presentan de modo similar tanto dentro de su ubicación en el ciclo de formación como en su vinculación con otras materias asociadas. Estos ámbitos de 
formación son: Teoría de la Administración; Derecho (en sus distintos niveles y acepciones); Economía; Sociología y Ciencia Política; Matemáticas y Estadística/ Métodos Cuantitativos (con diversos niveles y nomenclaturas).

Lo anterior se complementa con las asignaturas que serían el núcleo central y eje articulador (específico) sobre el que se construirían las bases del perfil profesional del futuro Administrador Público. Ellas son:

- Administración Pública

- Instituciones Políticas y/o Administrativas (en Chile)

- Gobierno y Administración del Estado

- Gobierno/Administración Regional y Local (Municipal)

- Diseño, formulación, implementación y evaluación de Políticas Públicas

- Políticas Públicas (Sectoriales)

- Reforma del Estado y Modernización de la Gestión Pública

- Gobierno Electrónico (explícito en solo dos casos)

- Probidad y Ética Pública (explícito en solo dos casos)

- Organismos y Relaciones (Políticas) Internacionales

Por otro lado, dichos planes de formación (comparados) se complementan con un fuerte componente de conceptos y herramientas prácticas ligadas a los temas de gestión, presupuesto, finanzas y contabilidad pública, y en menor medida, al ejercicio de la dirección pública, bajo diversas modalidades y contenidos. Los más característicos son:

- Gestión/Administración de Recursos Humanos

- Recursos Humanos por Competencias

- Diseño y Formulación de Proyectos

- Evaluación y Administración de Proyectos

- Planificación y Control de Gestión

- Diseño Organizacional y Gestión de Procesos

- Racionalización Organizacional / Organización y Métodos

- Diseño y Mejoramiento de Procesos

- Diseño de Sistemas 
- Presupuesto y Contabilidad (Pública/Gubernamental)

- Administración Financiera del Estado y/o Finanzas Públicas

- Análisis e Intervención Organizacional

- Dirección Administrativa y/o Estratégica de Organizaciones

- Planificación Estratégica

- Marketing Público y Gestión de la Imagen Corporativa

- Modelos de Decisiones

- Participación Comunitaria (explícito en un solo caso)

- Política y Estrategia

- Tecnologías de la Información/Software de Aplicación/Computación

Un detalle no menor y que merece ser destacado es que de las 10 mallas curriculares analizadas, solamente en cuatro casos encontramos como contenido formal y continuo en el proceso formativo y no como opción o electivo, el aprendizaje del "inglés" u otro idioma (Universidad de Chile con tres semestres bajo el rótulo de "idiomas"; Universidad de Concepción con cuatro semestres de inglés; Universidad Autónoma con dos semestres de inglés; y finalmente, la Universidad de Antofagasta con un semestre de idiomas), herramienta fundamental y cada vez más necesaria para moverse con soltura en el mercado laboral y sacar provecho de todas las potencialidades que supone el desarrollo profesional futuro.

Todo lo anterior, contrasta con la visible ausencia de espacios explícitos de formación en áreas vinculadas a competencias y/o destrezas. A nivel comparado, sólo se ha podido encontrar tres cursos y/o módulos que podrían asociarse al desarrollo de habilidades (básicas y directivas). A saber:

- Habilidades Gerenciales (explícito en un solo caso)

- Taller de Expresión Oral y Escrita

- Taller de Ensayo y Redacción

En síntesis, se observa un sesgo hacia la profesionalización en la carrera y la entrega de herramientas que permitan un correcto y adecuado desempeño laboral futuro en los egresados en comparación con la (casi inexistente) promoción y desarrollo de futuros académicos y/o investigadores en este ámbito disciplinario (donde dicho sea de paso, escasos esfuerzos sistemáticos existen actualmente en 
Chile comparado con otros países, tanto de la región como a nivel internacional). Ejemplo de ello es que al revisar todos los planes de estudio se verifica que los cursos sobre metodologías y técnicas de investigación (social, científica, cualitativa/cuantitativa) no sobrepasa del semestre, esto es que en un promedio de 5 años y/o 10 semestres de formación, solamente 1 semestre o medio año se le dedica a que los estudiantes accedan a comprender y trabajar con herramientas metodológicas que les permitan desarrollar investigación a futuro (lo que puede verse complementado en el ańo final de carrera bajo los cursos de apoyo para el trabajo de tesis de grado en algunos casos -y si correspondiese-). Ello nos parece complejo y demostrativo de la poca preocupación e interés por desarrollar futuros investigadores en la disciplina, espacio que se deja abierto para aquellos que sientan la motivación y el interés cursando programas de postgrado posteriores a la formación profesional de base ${ }^{12}$.

Contribuye además a despejar las claves de un debate permanente entre los que adhieren a la opción de aglutinar todo bajo la etiqueta de la ciencia política y quienes abogan por generar un espacio particular a quienes estudian administración pública, aun cuando uno de los pilares que la sustentan indisoluble e incuestionablemente sea, efectivamente, la primera. En el mundo de la academia y la investigación aplicada, son los cientistas políticos los que llevan la delantera y quienes dedican su noble oficio a dichas cuestiones, generando teoría, nuevos enfoques de análisis y tomándole el pulso al estudio del fenómeno del poder en las sociedades y sus derivados. Sin embargo, el Estado y sus instituciones (e inclusive más allá) requiere de profesionales que contribuyan a la conformación de cuerpos de excelencia que combinen en su justa medida una formación de primer nivel, una razonable vocación de servicio público y los conocimientos y competencias que es necesario desplegar para gestionar la cosa pública y agregar valor público: personas comprometidas y talentosas, preparadas y entusiastas, competentes y flexibles. Y al mismo tiempo, requiere adaptarse para atraer dicho talento y generar incentivos

12 En este punto conviene señalar que Chile ha avanzado bastante en los últimos diez años pues existe una vigorosa oferta de maestrías/magíster en el ámbito del gobierno, gestión y políticas públicas que, no obstante su sello orientado al perfeccionamiento profesional, actualización y profundización en áreas específicas del quehacer público (regulación, políticas sectoriales, etc.), se reconocen algunos programas con una aproximación más ligada a la investigación y desarrollo. Con todo y como antecedente adicional para el debate, a la fecha no existe ningún programa de doctorado específico en la materia en Chile (salvo la excepción de programas de doctorado en ciencia política como disciplina). 
apropiados para hacer de las organizaciones y servicios públicos una promesa atractiva de desarrollo profesional, laboral y por qué no, personal a quienes toman la opción y deciden ingresar a trabajar al sector público.

En este breve análisis y dada la información disponible, no consideramos los posibles contenidos y orientación formativa de los aprendizajes que se asocian a cursos electivos, de especialización, talleres y seminarios (de título, formación profesional, estudios aplicados u otros), y prácticas profesionales. Ello se entiende en el contexto de que por un lado, un importante porcentaje de estos cursos son espacios transversales de formación universitaria de carácter más general que favorece integrar miradas distintas en los futuros profesionales y que facilita el desarrollo de perspectivas que van más allá del perfil que define a la carrera. Por otro lado, en lo que respecta a electivos, muchos de éstos (sobre todo en los últimos semestres de la carrera) se asocian a ofertas disponibles (muchas de ellas sobre tópicos emergentes, nuevas tendencias u otros temas de especialidad y/o interés) sobre las cuales y dependiendo del número de interesados, se dictan o no. Dicha flexibilidad se reconoce como un mérito en la necesaria adaptación de contenidos para los futuros profesionales y, tal vez, como único espacio disponible para agregar nuevos enfoques disciplinarios y/o debates recientes en el desarrollo de la disciplina que permita adecuarla a contextos cada vez más globales y servir de ventana para mostrar y reflexionar sobre las tendencias emergentes en materia de gobierno, administración y políticas públicas en el mundo.

Adicionalmente, es necesario destacar que el análisis se desarrolló a partir de las mallas curriculares disponibles y publicadas en los sitios Web de las Universidades que actualmente imparten la carrera. En tal sentido y salvo las excepciones que se comentan, no se describen ni presentan de manera explícita los potenciales contenidos que integran la oferta de cursos bajo el rótulo de "electivo" o "taller/ seminario profesional”. De allí que es factible que exista algún tipo de omisión no intencionada al comentar comparativamente la oferta de contenidos disponible para la formación profesional del Administrador Público en las universidades chilenas y, a nuestro juicio, ello debiera contribuir a la entrega de información más detallada y específica sobre lo que es posible esperar de este tipo de cursos, sobre todo si se trata de "electivos de especialización" profesional. 
Para cerrar, y sobre la base de estos antecedentes, podemos comentar al menos los siguientes hallazgos de relevancia:

- Se trata de una carrera profesional más bien conservadora en sus contenidos (se reconocen espacios para adoptar nuevos enfoques sin que ello sea parte explícita en sus mallas curriculares);

- Sobre una base de integración de diversas disciplinas, se establece una columna vertebral que articula las áreas de administración, economía, derecho y ciencia política, como principales pilares formativos. De allí que en ocasiones se haga referencia a que el estudio de la "Administración Pública" (como verbo y sustantivo) sea una disciplina sincrética ${ }^{13}$;

- Adicionalmente, dispone de un robusto y articulado conjunto de herramientas técnicas y materias o cursos de carácter aplicado que son imprescindibles para el adecuado desempeño laboral y profesional de los egresados;

- Pese a los paradigmáticos cambios que se han generado en años recientes en el ámbito de la educación superior, en el plano laboral y profesional, en la ciencia y en la tecnología, y en la órbita de las competencias, habilidades y gestión del talento, no se observa, al menos curricularmente, que dichas tendencias hayan impactado en el diseño formativo de la gran mayoría de las universidades que imparten la carrera (salvo las excepciones detectadas), lo que puede constituir una brecha importante frente a otras carreras o disciplinas; supone una insuficiente actualización del perfil profesional del egresado y de lo que el mercado laboral espera de él; cuestiona las bases sobre las que se ha sustentado la carrera en sus más de 50 años de historia ${ }^{14} \mathrm{y}$, finalmente, pone en riesgo el despliegue de una serie de posibilidades (potenciales) que, trabajadas adecuadamente, podrían contribuir a reperfilar, posicionar y configurar nuevos espacios de desarrollo profesional en concordancia con el emergente debate sobre el rol del Estado y las administraciones públicas en ámbitos tan diversos como la gobernanza, las relaciones ínter-gubernamentales, la gestión de redes y transversalidad, el emprendimiento y la innovación pública, el enfoque de la administración pública deliberativa y la participación ciudadana, las estrategias de gobierno electrónico y Open Government, entre tantas otras.

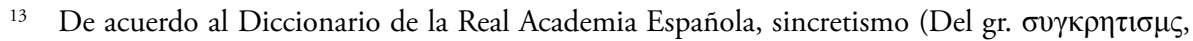
coalición de dos adversarios contra un tercero) apela a "un sistema filosófico que trata de conciliar doctrinas diferentes" (consulta del 7 de abril de 2011). Fuente: http://www.rae.es

14 Según consta en el sitio Web del INAP, el origen de la carrera se sitúa en la puesta en marcha de la Escuela de Ciencias Políticas y Administrativas dependiente de la Facultad de Ciencias Jurídicas y Sociales de la Universidad de Chile, que fuera creada por D. S. No 6.388 de 12 de agosto de 1954 del Ministerio de Educación, inaugurándose su primer período lectivo el 15 de abril de 1955. 
- En resumen, no somos una especie en extinción (todavía) pero ciertamente podemos llegar a serlo en los próximos ańos. De nosotros depende que ello no suceda.

En el siguiente acápite trataremos de hacernos cargo del enorme potencial que es posible desarrollar si cambiamos la mirada y asumimos que la reconfiguración de la profesión es un espacio lleno de ventajas y oportunidades que, ineludiblemente, debiéramos abrazar para protagonizar en primera persona los cambios que vienen, desde el Estado y sus instituciones, e inclusive más allá.

\section{4. ¿CÓMO SER ADMINISTRADOR PÚBLICO Y NO MORIR EN EL INTENTO? GUÍA PARA PROFESIONALES EN EL SIGLO XXI Y NOTAS PARA UN CAMBIO RADICAL Y PARA LA CONFIGURACIÓN DE UNA NUEVA MIRADA Y (R)EVOLUCIÓN DE LA CARRERA}

En años recientes, se ha venido desarrollando un interesante debate que ha llevado al mundo universitario el concepto de "competencias" como nuevo eslabón en la tarea por otorgar mayor consistencia y sustancia a los procesos formativos, y adecuar los diseños de planes de estudio a dicho enfoque. Al respecto, ser competente permite realizar una actividad con un nivel de dominio considerable correspondiente a un criterio establecido. El nivel de dominio que un individuo puede alcanzar en una tarea depende de los recursos con los que cuenta, involucra sus conocimientos, creencias, habilidades en diversos campos, destrezas, actitudes, valores, etc.

En esta perspectiva, educar con un enfoque basado en competencias significa crear experiencias de aprendizaje para que los estudiantes desarrollen habilidades que les permitan movilizar de forma integral recursos que se consideran indispensables para realizar satisfactoriamente las actividades demandadas. Se trata de activar eficazmente distintos dominios del aprendizaje; en la categorización más 
conocida, diríamos que se involucran las dimensiones cognitiva, afectiva y psicomotora (SEPM, 2008) $)^{15}$.

La forma como generalmente se determinan las competencias en el ámbito profesional implica identificar con precisión las funciones que una profesión demanda. A partir de ellas se determinan las competencias por niveles de complejidad, respondiendo a preguntas tales como ¿qué debe saber y saber hacer el profesional para cumplir con esta función?; ¡cómo debe hacerlo? Son las necesidades de la práctica profesional, completamente derivadas de la experiencia, las que determinan qué es lo que se ha de incluir en un currículo o plan de estudio basado en competencias profesionales (SEPM, 2008).

En tal sentido, se le ha dado un valor relevante al concepto aplicado de competencias genéricas en el perfil de egreso que describirían, fundamentalmente, conocimientos, habilidades, actitudes y valores, que son indispensables en la formación de los individuos que se despliegan y movilizan desde los distintos saberes; su dominio apunta a una autonomía creciente de los estudiantes tanto en el ámbito del aprendizaje como de su actuación individual y social. De manera adicional, estas competencias tienen un carácter transversal: no se restringen a un campo específico del saber ni del quehacer profesional; su desarrollo no se limita a un campo disciplinar, asignatura o módulo de estudios. La transversalidad se entiende como la pertinencia y exigencia de su desarrollo en todos los campos en los que se organice el plan de estudios. Además, son transferibles, en tanto que refuerzan la capacidad de los estudiantes de adquirir otras competencias (más específicas y/o ligadas a su dominio profesional particular).

En términos de nuestro análisis, pocas experiencias existen de las que se tenga evidencia sobre el proceso asociado y los resultados obtenidos aplicando el enfoque basado en competencias a la carrera de Administración Pública, aun cuando se reconoce que ha sido una tendencia en alza en el mundo universitario chileno. Sin

15 Una formación en competencias es una formación humanista que integra los aprendizajes pedagógicos del pasado a la vez que los adapta a las cada vez más complejas circunstancias del mundo actual. Se debe evitar confundir el concepto de competencias como se define en la educación con sus acepciones en el contexto del derecho y la economía (SEPM, 2008). 
embargo, creemos que ello poco a poco irá penetrando en el debate y ya existen algunas interesantes iniciativas en esta dirección ${ }^{16}$.

Si bien reconocemos que el enfoque basado en competencias agrega valor al proceso formativo y resulta ser una potente herramienta para rearticular los planes de estudio, las metodologías de aprendizaje y los contenidos curriculares, es necesario dejar de manifiesto que ella es un medio para perfeccionar estas tareas y no un fin en si mismo. Como sabemos, las competencias se orientan a garantizar la producción de resultados y no al mero almacenamiento de saberes (como ha sido la tradición en la formación universitaria hasta fines del siglo XX), pero hay que ser prudentes al intentar reducir de manera simplista el concepto vital de "formación profesional" al mero despliegue de ciertas "competencias", sobre todo en un contexto vinculado al terreno de las ciencias sociales y de tradición eminentemente humanista.

\subsection{De las competencias a las habilidades... ¡Y más allá!}

Lo anterior contrasta con la existencia de diversas visiones orientadas a apoyar los procesos formativos que, más allá de incluir el enfoque basado en competencias, se preocupan por las variables de contexto que enfrentarán quienes busquen emplearse en un mundo cada vez más complejo, interconectado y plano. Un ejemplo interesante de estos aportes es el estudio de Wagner (2008), quien propone siete habilidades fundamentales para enfrentar los cambios y redefiniciones de esta era globalizada. Según este autor las principales habilidades (soft skills) que contribuirían a una mejor formación de la fuerza laboral en el siglo XXI son:

1. La solución de problemas y pensamiento crítico;

2. Colaboración a través de redes de cooperación e influencia;

3. Agilidad y capacidad de adaptación;

4. Iniciativa y espíritu de empresa/organización;

16 Es el caso del Proyecto ULA0807 "Rediseño Curricular basado en competencias y aseguramiento de los aprendizajes de los alumnos de las carreras de Administración Pública de las Universidades de Los Lagos, Concepción, Valparaíso y Antofagasta" (año 2010), cuya propuesta se orienta a que tanto el currículo como las prácticas de enseñanza deberán apuntar hacia las demandas presentes y futuras de la profesión, de modo que la formación se constituya en un instrumento para el desarrollo de las capacidades de pensar, actuar y participar en los cambios (Proyecto ULA0807). 
5. Eficacia comunicacional, escrita y oral;

6. Capacidad para acceder y analizar información, y

7. Curiosidad e imaginación.

Wagner postula que tanto en el mundo del trabajo como en el del aprendizaje es básico desarrollar la capacidad de pensar. Es decir, razonar, analizar, ponderar evidencias y tener la habilidad para resolver problemas y para comunicarse de manera efectiva. Todo ello expresa y deja en evidencia la necesidad de una mirada renovada e integral sobre este tipo de cuestiones, sobre todo al aplicarlo a la formación de Administradores Públicos.

Una mirada más cercana es la que ha venido desarrollando históricamente el Programa de Habilidades Directivas (PHD) del Departamento de Ingeniería Industrial de la Universidad de Chile, en la formación de ejecutivos y líderes del sector público, de donde hemos querido rescatar un listado de aquellas destrezas (para la gestión) que se asume son fundamentales para el ejercicio de los profesionales en el tercer milenio (partiendo por el "aprender a aprender") ${ }^{17}$. Traerlas a la mano ahora nos parece del todo conveniente para cristalizar la propuesta que ofrecemos en el camino a generar una transformación radical en la formación de Administradores Públicos. Ellas son:

1. Comunicar: entendida como la capacidad de generar acción efectiva y coordinaciones de acciones efectivas en los equipos de trabajo;

2. Liderar: entendido como la capacidad para generar, participativamente, proyectos de desarrollo e innovación que generan entusiasmo y compromiso en los equipos de trabajo;

3. Trabajar en Equipo: entendido como la capacidad para diseñar y llevar adelante proyectos y todo tipo de coordinaciones, en forma eficaz, eficiente y con bienestar, en condiciones de alta diversidad de los miembros del equipo, en términos de formas de ver, ser y hacer;

17 Las habilidades o destrezas son conceptualizadas como "respuestas automáticas adecuadas" frente a un conjunto de situaciones características y recurrentes de la gestión moderna. La adquisición de destrezas no consiste en la adquisición de conocimientos que conscientemente se aplican en determinadas circunstancias, sino en la generación de formas nuevas de respuesta -conductas nuevas, actitudes nuevas, estados de ánimo nuevos, etc.- que se manifiestan en determinadas situaciones. 
Continuación

4. Innovar: entendida como la capacidad de generar nuevos espacios de posibilidades, viables, coherentes, consistentes y rentables;

5. Negociar: entendida como la capacidad para llegar a acuerdos en condiciones de diferencias de intereses, posiciones y visiones;

6. Escuchar: entendida como la capacidad de generar interpretaciones poderosas, que se hagan cargo adecuadamente de los actores y los fenómenos involucrados en una determinada circunstancia o ámbito. Ello involucra un conjunto de ámbitos diversos de observación: intereses, preocupaciones, discursos, estilos, prácticas, contextos, presiones, redes, estados de ánimo, quiebres;

7. Aprender: entendida como la capacidad para adquirir, en forma eficaz y eficiente, nuevas capacidades de acción. El aprender está por cierto determinado por la capacidad de escuchar, declarar ignorancia, dar autoridad y ser riguroso en las prácticas;

8. Seducir: entendida como la capacidad para hacer ofertas o pedidos que resulten atractivos a otros y que conduzcan a acciones que favorezcan a ambos;

9. Especular: entendida como la capacidad para generar, sostener y hacer converger conversaciones tentativas de diseño;

10. Evaluar: entendida como la capacidad para generar, sostener y hacer converger conversaciones de intercambio de juicios, positivos y negativos, especialmente referidos a acciones y competencias humanas;

11. Delegar: entendida como la capacidad de administrar eficaz y eficientemente los compromisos de un equipo, a través de la utilización de las capacidades e intereses de los miembros del equipo;

12. Declinar: entendida como la capacidad para denegar, en forma adecuada y rápida, peticiones a las cuales se tiene o se desea declinar; $y$

13. Reclamar: entendida como la capacidad para cobrar compromisos, renegociar compromisos no cumplidos cuando las condiciones lo hacen necesario.

Fuente: Manual de Habilidades Directivas (2003)

\subsection{De las habilidades al futuro (digital) del trabajo: ¿Profesionales Di- gitales versus Mundos Analógicos (Burocracia Pública) o Mundos Digitales versus Profesionales Analógicos?}

En un reciente artículo, Cobo (2010) identifica los distintos aportes relacionados con el perfil de un trabajador del siglo XXI, y a continuación propone un esquema conceptual complementario (en ningún caso excluyente) que busca articular 
diversas fuentes académicas y/o provenientes de organismos internacionales. El fin de este ejercicio ha sido identificar aquellas competencias vinculadas al uso de las tecnologías digitales y la gestión del conocimiento, que pudiesen apoyar el desempeño laboral de quienes trabajan en la era de la información y, sobre dicho marco, se propone la definición del término "e-competencias": Capacidades para la gestión de conocimiento tácito y explícito, empoderada por la utilización de las TIC y el uso estratégico de la información. Las e-competencias van más allá de la utilización de una TIC en particular, ya que también incluyen conocimientos y actitudes orientadas al trabajo colaborativo, la innovación y el aprendizaje constante, así como la creación de nuevas ideas para enfrentar problemas desconocidos en diversos contextos (Cobo, 2010).

Así, se propone un perfil de trabajador e-competente que estaría constituido por cinco habilidades fundamentales:

1. E-Conciencia: Esta habilidad cognitiva se caracteriza por la comprensión del papel que juegan las TIC en la sociedad de la información. Está basada en el entendimiento de cómo estos instrumentos pueden resultar perjudiciales y/o benéficos para el desarrollo de la sociedad. Es un acto de cognición influenciado por los crecientes flujos de información y conocimiento orientado a la generación de valor agregado en diversos contextos. Un usuario e-conciente cuenta con la capacidad de entender y responder a los desafíos de una sociedad que asigna especial importancia a la idea de "aprendizaje para toda la vida". Este entendimiento incluye la habilidad para vincular los ámbitos sociales, culturales, legales y éticos relacionados a las TIC ("ciudadania digital").

2. Alfabetismo Tecnológico: Este alfabetismo guarda relación con el uso diestro de los medios electrónicos tanto para estudiar y trabajar como para el ocio. Está representado por la habilidad de interactuar tanto con hardware y software así como con aplicaciones vinculadas con la productividad, la comunicación o la gestión. Este alfabetismo incluye el uso estratégico de Internet y otras vías electrónicas de comunicación para actividades como: generar redes de colaboración, intercambio de información, trabajo a distancia, entre otras. Las tecnologías incluidas en esta competencia evolucionan de acuerdo a la transformación de las TIC. 
Continuación

3. Alfabetismo Informacional: Es la habilidad de comprender, evaluar e interpretar información proveniente de diferentes fuentes. El concepto de alfabetismo informacional va mucho más allá que la capacidad de leer, puesto que significa leer con significado, entender críticamente y al mismo tiempo ser capaz de analizar, ponderar, conectar e integrar diferentes informaciones, datos y conocimientos. Requiere la capacidad de hacer juicios informados en relación a aquello que se encuentra dentro o fuera de Internet. Incluye la capacidad de evaluar el grado de confiabilidad y calidad de la fuente, determinando cómo y cuándo la información es apropiada para una determinada audiencia o contexto.

4. Alfabetismo Digital: Es la capacidad para generar nuevo conocimiento apoyado en el uso estratégico de las TIC. Los principales aspectos vinculados con la alfabetización digital combinan la habilidad para conseguir información relevante (dimensión instrumental), así como producir y administrar nuevo conocimiento (dimensión estratégica). Estar alfabetizado digitalmente implica utilizar las TIC para acceder, almacenar, organizar, integrar, y compartir información y conocimiento en múltiples formatos.

5. Alfabetismo Mediático: Este alfabetismo tiene que ver con comprender cómo los medios de comunicación tradicionales están transformándose dentro del entorno de los medios electrónicos. Esta habilidad incluye el entendimiento de cómo funcionan los medios, cómo evolucionan hacia nuevos formatos, sus plataformas y modos de interacción. Finalmente, incluye el saber cómo los medios producen y generan significado así como sus implicancias sociales, legales, políticas y económicas.

Fuente: Cobo (2010).

Como vemos, estas competencias debieran ser asumidas por cualquier trabajador en la era del conocimiento y la información. Y todo ello va más allá del mero cambio instrumental, pues la transformación que está facilitada por la tecnología digital es más profunda y afecta a nuestras prácticas y valores (Freire, 2010). Ello (lamentablemente) no está presente de manera explícita en el debate sobre nuestros planes de formación. 


\subsection{De la Sociedad y el Estado Red al "Hágalo Usted mismo": Los nue- vos enfoques de Modelos de Educación Abierta (y su contribución al desarrollo profesional)}

Siguiendo la seminal reflexión de Maturana (y reseteada por el Cluetrain Manifesto, 2008), diremos que las carreras profesionales son "conversaciones", como flujo de coordinaciones recurrentes de haceres que van configurando una cierta manera de ver, entender, estar y actuar en el mundo, para los estudiantes. Visto así, la particularidad en la que reside la configuración profesional obedecería principalmente a entender los fenómenos sociales ligados con lo que tradicionalmente hemos llamado "poder". Dicho espacio se ha visto expandido y amplificado por el uso intensivo de las nuevas tecnologías y las llamadas redes sociales o Web 2.0 (Castells, 2009), que inclusive ha generado una nueva mirada sobre la sabiduria de las masas al momento de pensar, diseñar e implementar determinadas políticas públicas bajo el concepto de Wikigovernment (Noveck, 2009), en oposición a la tradicional postura tecnocrática y eficientista de los gobiernos. Y también podemos traer a la mano los recientes acontecimientos ligados a las revoluciones en el mundo árabe donde las redes sociales han tenido un rol catalizador importante en dichos procesos $^{18}$.

Todo lo anterior como preámbulo para explicar brevemente el reciente fenómeno de transformación educativa abierta basado en los nuevos escenarios tecnológicos, la sociedad en red y los flujos de información y gestión de conocimiento denominado como DIY (Do-It-Yourself / "Hágalo Usted Mismo") (Kamenetz, 2010) o EduPunk. Este (aún disperso) enfoque, se vincula a modelos de apertura educativa, espacios de convivencia y entornos de aprendizaje (en comunidad) que, en términos prácticos, significan la expansión de la educación más allá de las paredes

18 Recordemos que los profesionales que se incorporarán al mercado laboral durante la próxima década nacieron en medio del sonido del grunge y el britpop, en los primeros años de la década de los '90. Eran muy pequeños para cuando Internet inició su conquista y el correo electrónico comenzó (tímidamente) a reemplazar nuestra habitual forma de comunicarnos, mientras en paralelo los hogares comenzaban poco a poco a recibir a sus nuevos inquilinos: los ordenadores personales y los primeros portátiles. Sin embargo, desde el punto de vista cognitivo constituyen lo que se ha venido denominando como "nativos digitales", una especie de ser humano que se ha ido configurando al alero del uso intensivo de las tecnologías. 
del aula ${ }^{19}$ : gratuita, de código abierto, de formación profesional y vocacional, en base a la experiencia y sobre la base de aprendizaje autodirigido. Una interesante forma de comprenderlo se expresa en un manifiesto cuyo atractivo deriva en la crítica de fondo a los principios que constituyen nuestra manera de entender la educación superior (Cuadro 2).

\section{Cuadro 2 Manifiesto EduPunk}

- Las clases son conversaciones.

- La relación es dinámica y la dinámica es relacional.

- Sea hipertextual y multilineal, heterogéneo y heterodoxo.

- EduPunk no es lo que pasa en el aula, es el mundo en el aula.

- Sea como el caminante... haga camino al andar.

- Sea mediador y no medidor del conocimiento.

- Rómpase la cabeza para crear roles en su comisión; cuando los cree, rómpales la cabeza.

- Sus roles deben ser emergentes, polivalentes, invisibles.

- Asuma el cambio, es solo una cuestión de actitud.

- Siéntase parte de un trabajo colectivo.

- No sea una TV, interpele realmente a los que lo rodean.

- Expanda su mensaje, haga estallar las cuatro paredes que lo rodean.

- Mezcle, cópiese, aprópiese, curiosee, juegue, transfórmese, haga, derrape.

- Al carajo con la oposición real/virtual.

- Sin colaboración, la educación es una ficción.

- Sea un actor en su entorno, investigue a través de la acción.

- Hágalo usted mismo... pero también y esencialmente, hágalo con otros.

- Sea EduPunk, destruya estas reglas, cree las suyas y luego, destrúyalas.

Fuente: http://www.edupunkmanifesto.org/ (agosto de 2010).

Una forma distinta de ver el mismo fenómeno podemos encontrarla en el encuentro y la colaboración activa entre funcionarios y ciudadanos. Se desvanecen las mutuas desconfianzas, se establecen nuevos canales de comunicación, se "personaliza" el contexto conversacional, se humaniza la administración pública.

$19 \mathrm{Y}$ el problema principal es que nuestros inmigrantes digitales (los profesores), que hablan un lenguaje obsoleto (propio de la era pre-digital), están luchando por enseñar a una población que habla un lenguaje completamente diferente (los estudiantes, en su mayoría nativos digitales). Allí, la clave de la paradoja. 
Comienza un tránsito virtuoso entre hackers ${ }^{20}$ y técnicos especialistas en políticas públicas, entre quienes poseen conocimiento experto y los que aportan con nuevas formas de pensar y aplicar herramientas tecnológicas para facilitar, recrear, reinventar, hacer florecer innovadores y radicales cambios en la relación entre las instituciones públicas y la sociedad en su conjunto. Gran parte de este debate se cristaliza en el llamado Open Government y en sus principios de transparencia, participación y colaboración (Ramírez-Alujas, 2010).

\section{ALGUNAS CONCLUSIONES: EL IMPERATIVO POR REDESCUBRIRUN PERFIL PROFESIONAL ABIERTO Y LA OPORTUNIDAD DE SER UNA NUEVA ESPECIE PROFESIONAL EMERGENTE PARA EL SIGLO XXI}

Más allá de las conjeturas que hemos tratado de esbozar en este artículo y las reflexiones que surgen como puertas abiertas a nuevas aproximaciones al tema, existen un par de ideas que cristalizan el anhelo que subyace como hilo conductor del propósito y oportunidad de detenernos a observar lo que ocurre en nuestros espacios vocacional, profesional y laboral. Una de estas ideas se relaciona al concepto del "Elemento", recientemente esgrimido por Sir Ken Robinson (2009), donde se plantea que "las personas que están en su elemento encuentran gran deleite y placer en lo que hacen" ${ }^{21}$. Trataré de explicarlo con un ejemplo personal:

20 Entendemos la "ética hacker" como alguien que trabaja en algo que le apasiona y comparte sus conocimientos con otros, colaborando en la creación de nuevos mundos, una suerte de individualismo comunitario... un espacio donde las personas trabajan activamente para contribuir al bien común, por el simple placer de hacerlo. En esta línea conviene conocer y reflexionar acerca del Manifiesto de los Funcionarios Emprendedores en España, como ejemplo: http:// funkzionatas.wordpress.com/manifiesto/

21 De acuerdo a Robinson, el Elemento es el punto de encuentro entre las aptitudes naturales y las inclinaciones personales [...] Cuando las personas están en su elemento establecen contacto con algo fundamental para su sentido de la identidad, sus objetivos y su bienestar. Experimentan una revelación, perciben quiénes son realmente y qué deben hacer con su vida [...]. Además, supone la existencia de dos características principales (capacidad y vocación) y dos condiciones (actitud y oportunidad) para estar en él. La secuencia que sigue dicho proceso es: lo entiendo; me encanta; lo quiero; ¿¿dónde está? (Robinson, 2009). 
En la Facultad de Ingeniería de la Universidad de Chile, donde trabajé durante unos años, solíamos comentarles a nuestros estudiantes de los cursos finales sobre capacidad emprendedora e innovación -cuya orientación potencial a esas alturas de la carrera era salir a competir al mercado lo antes posible, ganar un buen salario en un corto plazo y acceder a una posición gerencial- que "cuando uno hace (trabaja en) algo que le gusta y se siente satisfecho y pleno llevándolo a cabo, los recursos (dinero) llegan solos". Con ello queríamos graficar la idea que lo principal en la vida profesional y laboral es sentirse cómodo, enamorado y conectado emocionalmente con el oficio que se ejerce pues de ese modo es factible una combinación excepcional entre los talentos, pasiones que nos mueven, vocación que nos motiva; despliegue de habilidades, competencias y destrezas que, en última instancia, se expresan en una carrera (profesional) exitosa, en gozar y disfrutar a cada instante con lo que se hace y crear una identidad (laboral) que favorece la movilidad, el encontrar y desarrollar nuevas iniciativas, y lograr evitar caer en ese estado que nos recuerda la letra de un poema de Facundo Cabral: "Todo aquel que no ama en lo que trabaja, aunque trabaje todo el día, es un desempleado”.

En resumen, si de lo que se trata es de apoyar la formación integral de un profesional competente, flexible y abierto a los nuevos desafíos laborales en un entorno en permanente dinamismo y cambio, lo que tenemos disponible como base formativa común -en la forma y en el fondo- en las universidades que otorgan el título de Administrador Público, es condición necesaria pero insuficiente para alcanzar adecuadamente dicho propósito. Basta con mirar los contenidos vertebrales comparados entre las carreras, las disciplinas y cátedras que tienen un peso relativo mayor en los planes de estudio para constatar que el cambio de paradigma que ha experimentado la sociedad red global en los últimos 20 años -y por ende, la política, el Estado y sus instituciones- no tiene correspondencia alguna con el tipo de perfil profesional (deseable) que se requeriría para acometer exitosamente la adaptación a los nuevos y emergentes contextos que les tocará enfrentar a los actuales y nuevos egresados. No nos engañemos, sustituyendo enfoques obsoletos por miradas más vanguardistas o de moda no nos alcanza (sobre todo si sólo son cambios cosméticos o de fachada), como tampoco confiar en que por la vía del incrementalismo se pueda llegar a resolver el fondo del asunto. En definitiva, necesitamos cambios y éstos, aunque nos incomoden, deben ser radicales. 
Si en Chile pretendemos liderar los caminos de futuro en materia de asuntos públicos, debemos partir por analizar descarnadamente las brechas que nos alejan de los centros de referencia a nivel mundial y adecuar nuestra mirada a diseñar acciones que nos permitan hacernos cargo de ello lo antes posible. Tal desafío no sólo pasa por potenciar el terreno de la investigación aplicada en los ámbitos de la Administración Pública, estudios políticos, análisis de políticas públicas, entre tantos otros, sino que debe ir acompañado de la generación de una "escuela de pensamiento" propio que, aprovechando la posición, liderazgo y el prestigio que Chile tiene en estos temas, por lo menos a nivel latinoamericano, sobre la seriedad y robustez institucional con la que ha llevado a cabo las transformaciones del Estado y los procesos de modernización del sector público en los últimos 20 años (que coincide con el proceso de democratización vivido por el país), sirva de plataforma de base para desarrollar un nuevo marco de trabajo que articule, condense y sistematice dichos aprendizajes, herramientas, procesos, productos y/o servicios, y los convierta en una especie de cluster académico innovador y en una red de formación, investigación y asistencia técnica de excelencia, tanto para Chile como para el resto de países de la región.

Chile tiene reconocidas ventajas en estas materias y sólo se requiere del compromiso de sus actuales escuelas de administración pública para alcanzar un acuerdo de estas características. Pensar en una red nacional de formación e investigación aplicada que cohesione y articule a todas estas escuelas sería un paso enorme e inclusive podría contribuir directamente a los esfuerzos por profesionalizar la función pública que viene desarrollando desde el año 2004 la Dirección Nacional del Servicio Civil (DNSC) y el Sistema de Alta Dirección Pública ${ }^{22}$. Al mismo tiempo, la apertura como signo de los tiempos que vivimos, nos invita a colaborar de manera estrecha con otras disciplinas y/o espacios profesionales, ya que de ello depende en gran medida el desafío por estar a la vanguardia y catalizar los múltiples esfuerzos que se llevan a cabo para fortalecer la acción del Estado y el mejoramiento de los servicios públicos. Debemos admitir que ello no es privativo y exclusivo del ejercicio de un oficio o profesión particular. Históricamente nuestro país se ha forjado sobre la base del liderazgo de estadistas, directivos y

22 Recordemos que Chile es uno de los pocos países iberoamericanos que no cuenta con una institucionalidad pública (como instituto o centro de estudios) en materia de investigación, asistencia técnica, formación y perfeccionamiento para los directivos y funcionarios públicos (Ramírez-Alujas, 2004). 
funcionarios cuyas profesiones son tan variadas como la vida misma: abogados, ingenieros, economistas, médicos, profesores, etc.

Si el lector (asumimos una persona genuinamente interesada en estos temas) ha llegado hasta aquí, lo agradecemos y es menester reconocerlo. A estas alturas podrá estar en acuerdo o desacuerdo con los argumentos, síntesis y reflexión presentada. Pero ello no es lo realmente importante. Lo que nos interesa es el espacio que se abre para cultivar nuevas semillas y cosechar una renovada disciplina, robusta y orgullosa, rigurosa y vanguardista, flexible y adaptable a los cambios que se viven en el mundo al que servirá como oficio. Una profesión que mezcle arte y ciencia, que en nuestros días debiera evocar al trabajo del artesano, que combina una incondicional entrega a su quehacer y una pasión casi mística con su obra con un profundo sentido de la intuición, preocupación por los detalles, la búsqueda de la perfección y la fluidez en las circunstancias. Senge (2002) ilustra este proceso como una danza.

De allí que debiéramos pensar en la creación de una escuela de líderes y emprendedores sociales más que en encapsular nuestra formación en compartimentos estancos con un perfil único y rígido, y ello significa abrir las ventanas de la disciplina profesional para que el aire fresco (de las nuevas realidades que trae un mundo en transición permanente) revitalice sus pasillos y llene de nuevas preguntas, enfoques, miradas y tradiciones la reflexión-acción que hoy se requiere para liderar estos tiempos. Pensar en laboratorios de aprendizaje e innovación, en comunidades de práctica, en círculos reflexivos, en apertura educativa y profesional, etc. Ello podría concretarse de manera sencilla mediante iniciativas y trabajo conjunto con municipios, servicios públicos y organizaciones no gubernamentales que se ocupen de resolver problemáticas públicas, permitiendo que los estudiantes tengan un acercamiento práctico desde sus primeros años de formación universitaria, trabajando desde y con la realidad en espacios tutelados o configurados como prácticas intermedias (bajo el esquema de proyectos específicos de intervención), que posibiliten un capital de experiencias acumuladas (virtuosas) en el fortalecimiento del binomio conocimientos-competencias que redunden en una aproximación hacia la cosa pública más allá de los límites de lo propiamente estatal (como futuro espacio laboral preferente). 
Resulta fundamental el tomar en serio la incorporación de espacios formales para el aprendizaje de habilidades dentro de los planes de estudio. En la actual coyuntura resulta imperativo que los programas formativos articulen y desarrollen de manera simultánea los aspectos cognitivos (conceptuales y analíticos) con aquellos asociados a las habilidades (destrezas y competencias en materia de gestión). Ello es clave en la configuración integral de un profesional abierto al cambio, competente, adaptable y flexible en el tránsito hacia el mundo laboral. Dicho objetivo podría materializarse mediante la inclusión de módulos o talleres de desarrollo de habilidades que crucen transversalmente el proceso de formación y/o como dispositivos de apoyo metodológico en algunos dominios o materias específicas. Con todo, dichos ajustes suponen modificaciones de forma más que de fondo, cuyo éxito radica en asumir el valor de incorporar estos espacios de aprendizaje y articularlos adecuadamente con el perfil de egreso y con la apertura del enfoque disciplinario que, tradicionalmente, alberga la carrera. En tal sentido, se sugiere considerar al menos tres dimensiones para el diseño y puesta en marcha de este tipo de propuestas de aprendizaje: a) La existencia de un cuerpo de distinciones coherentes y consistentes (una ontología); b) El contar con un entorno favorable al aprendizaje (un "gimnasio"); y c) La recurrencia en la práctica de las acciones conducentes al aprendizaje.

Finalmente y no menos importante, no debemos olvidar que en nuestras escuelas universitarias formamos profesionales pero también ciudadanos. Y jamás tendremos buenos gobiernos y administraciones públicas sin partir primero por contar con buenos ciudadanos.

\section{REFERENCIAS BIBLIOGRÁFICAS}

Castells, Manuel (2009). Comunicación y Poder. España: Alianza Editorial.

Cobo Romaní, Cristóbal (2010). "Cultura digital y nuevos perfiles profesionales: desafíos regionales”, @tic. Revista d'innovació educativa No 5, pp-1-7 http://ojs.uv.es/index.php/attic/ article/view/187

Comisión Nacional de Acreditación de Pregrado - CNAP (2007). Marco de referencia para los procesos de acreditación \& Documentos sobre perfil de egreso y planes de estudio para la carrera de Administración Pública. (Mimeo). Chile: Ministerio de Educación. 
Freire, Juan (2011). “Tecnología y educación: ¿nuevos instrumentos para objetivos obsoletos?” Boletin del CCTAE. Disponible en: http://www.tendenciaseducativas.es

Kamenetz, Anya (2010). DIYU (Do-It-Yourself University): Edupunks, Edupreneurs, and the Coming Transformation of Higher Education. USA: Chelsea Green Publishing.

Levine, Rick; Locke, Christopher; Searls, Doc; Weinberger, David (2008). El Manifiesto Cluetrain. Barcelona: Ediciones Deusto.

Maturana, Humberto (1989). Emociones y lenguaje en educación y politica. Santiago: CED.

Noveck, Beth Simone (2009). Wiki Government: How technology can make government better, democracy stronger, and citizens more powerful. Washington: Brookings Institution Press.

Programa de Habilidades Directivas (2003). Manual de Habilidades Directivas. Documento de Trabajo, Departamento de Ingeniería Industrial, Universidad de Chile.

Proyecto ULA0807 (2010). "Rediseńo Curricular basado en competencias y aseguramiento de los aprendizajes de los alumnos de las carreras de Administración Pública de las Universidades de Los Lagos, Concepción, Valparaíso y Antofagasta” (Mimeo).

Ramírez-Alujas, Álvaro V. (2010). "Innovación en la Gestión Pública y Open Government (Gobierno Abierto): Una vieja nueva idea”. Revista Buen Gobierno $\mathrm{N}^{\circ} 9$.

Ramírez-Alujas, Álvaro V. (2004). "El proceso de reforma del Estado y de modernización de la gestión pública en Chile: Lecciones, experiencias y aprendizajes (1990-2003)". Madrid: Instituto de Administración Pública (INAP) - Ministerio de Administraciones Públicas (MAP).

Robinson, Ken (2009). El elemento. Descubrir tu pasión lo cambia todo. Barcelona: Grijalbo.

Secretaría de Educación Pública de México - SEPM (2008). Competencias genéricas que expresan el perfil del egresado de la educación media superior. México: Subsecretaría de Educación Media Superior.

Senge, Peter (2000). La danza del cambio: los retos de sostener el impulso en organizaciones abiertas al aprendizaje. Colombia: Editorial Norma.

Wagner, T. (2008). The Global Achievement Gap. Philadelphia: Basic Books.

\section{Sitios Web:}

Servicio de Información de Educación Superior (SIES) del Ministerio de Educación (Chile). Consulta sobre la carrera de Administración Pública y Ciencias Políticas:

http://www.futurolaboral.cl/index.php?option=com_content\&view=article\&id=46\&carrID=2\&It emid=29 


\section{Universidades}

(Consultas realizadas durante los meses de febrero - marzo de 2011)

\begin{tabular}{|c|c|}
\hline Universidad de Chile & http://www.inap.uchile.cl/ \\
\hline Universidad de Antofagasta & $\begin{array}{l}\text { http://www.uantof.cl/carreras/Administración\%20 } \\
\text { Publica/Adm.Publica.jefe.html }\end{array}$ \\
\hline Universidad de Concepción & http://www2.udec.cl/cpoliticas/ \\
\hline Universidad de Los Lagos & http://www.ulagos.cl \\
\hline Universidad de Valparaíso & $\begin{array}{l}\text { http://www.uv.cl/carreras/?c=1968 } \\
\text { www.administracionpublica-uv.cl }\end{array}$ \\
\hline $\begin{array}{l}\text { Universidad de } \\
\text { Santiago de Chile }\end{array}$ & http://www.fae.usach.cl/ \\
\hline $\begin{array}{l}\text { Universidad Academia de } \\
\text { Humanismo Cristiano }\end{array}$ & $\begin{array}{l}\text { http://admision2011.academia.cl/carreras/administracion- } \\
\text { publica }\end{array}$ \\
\hline $\begin{array}{l}\text { Universidad Autónoma de } \\
\text { Chile }\end{array}$ & $\begin{array}{l}\text { http://www.uautonoma.cl/admision2011/administracion } \\
\text { publica.php }\end{array}$ \\
\hline Universidad Central & $\begin{array}{l}\text { http://www.ucentral.cl/prontus_fcpa/site/artic/20080727/ } \\
\text { pags/20080727104906.html }\end{array}$ \\
\hline Universidad San Sebastián & $\begin{array}{l}\text { http://admision.uss.cl/carreras/ciencias-politicas-y- } \\
\text { gestion-publica }\end{array}$ \\
\hline
\end{tabular}

Recibido: 18/04/2011

Aprobado: 28/06/2011 